\title{
THE CHEMICAL ENGINEERING SIDE OF NUCLEAR FUSION POWER
}

BY

ERNEST F, JOHNSON

\section{PLASMA PHYSICS LABORATORY}

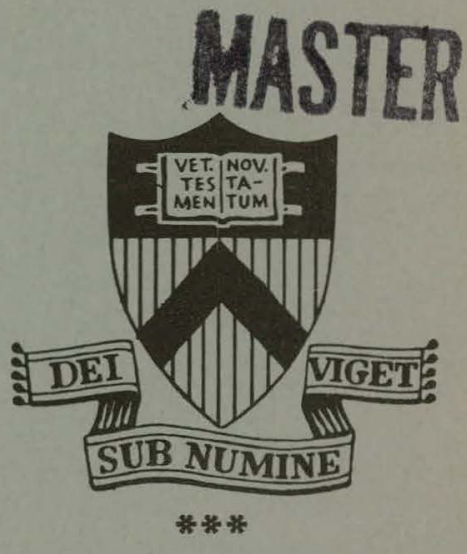

\section{PRINCETON UNIVERSITY PRINCETON, NEW JERSEY}

This work was supported by U. S. Energy Research and Development Administration Contract E(11-1)-3073. Reproduction, translation, publication, use and disposal, in whole or in part, by or for the United States Government is permitted. IHIS DOCUMEMI LS LINLMITED 


\section{DISCLAIMER}

This report was prepared as an account of work sponsored by an agency of the United States Government. Neither the United States Government nor any agency Thereof, nor any of their employees, makes any warranty, express or implied, or assumes any legal liability or responsibility for the accuracy, completeness, or usefulness of any information, apparatus, product, or process disclosed, or represents that its use would not infringe privately owned rights. Reference herein to any specific commercial product, process, or service by trade name, trademark, manufacturer, or otherwise does not necessarily constitute or imply its endorsement, recommendation, or favoring by the United States Government or any agency thereof. The views and opinions of authors expressed herein do not necessarily state or reflect those of the United States Government or any agency thereof. 


\section{DISCLAIMER}

Portions of this document may be illegible in electronic image products. Images are produced from the best available original document. 
NOTICE

This report was prepared as an account of work sponsored by the United States Government. Neither the United States nor the United States Energy Research and Development Administration, nor any of their employees, nor any of their contractors, subcontractors, or their employees, makes any warranty, express or implied, or assumes any legal liability or responsibility for the accuracy, completeness or usefulness of any information, apparatus, product or process disclosed, or represents that its use would not infringe privately owned rights.

Printed in the United States of America.

Available from

National Technical Information Service

U. S. Department of Commerce 5285 Port Royal Road

Springfield, Virginia 22151

Price: Printed Copy \$_*; Microfiche $\$ 3.00$

*Pages
$1-50$
$51-150$
$151-325$
$326-500$
$501-1000$

NTIS

Selling Price

$\$ 4.00$

5.45

7.60

10.60

13.60 
The Chemical Engineering Side of Nuclear Fusion Power

Ernest F. Johnson

Department of Chemical Engineering and

Plasma Physics Laboratory

Princeton University

Princeton, New Jersey 08540

PPPL-1303

October 1976 
The Chemical Engineering Side of Nuclear Fusion Power

\author{
Ernest F. Johnson \\ Department of Chemical Engineering and \\ Plasma Physics Laboratory \\ Princeton University \\ Princeton, New Jersey 08540
}

\begin{abstract}
It is widely recognized that chemical engineering has important roles to play in the development of national and world wide energy resources through optimal utilization of fossil fuel reserves. It is much less appreciated that there are crucial chemical engineering problems in the development of energy production from other sources. In particular the successful development of nuclear fusion power generating ogotems will require the solution of many problems that are uniquely suited to chemical engineers.

This article presents a brief overview of the fusion development program and an identification of the major technological problems remaining to be solved.
\end{abstract}




\section{$\therefore-2-$}

\section{SCOPE}

A major purpose of this review is to alert chemical engineers to the technological obstacles that beset the path to the development of fusion power machines to the end that there will be increased participation in the development effort by those engineers and scientists best qualified to solve the problens." We first examine the potential importance of fusion power in the national and global energy economy and the relative "urgency of its development. Next we present a realistic. perspective on the likely timetable for the development based in part on past history in the program and largely on current planning strategies. And finally we describe the likely characteristics of fusion machines as a basis for identifying the major technological problems and the current state of the efforts to solve them.

\section{Energy Perspective}

Despite the large areas of ignorance and the enormous uncertainties which obscure attempts to forecast anything, it is inescapably clear that for the intermediate term, say to the year 2000, world population will continue to grow, 'the global per capita demand for energy, in particular electric power, will grow, and the available fossil fuels will decline in amount, and their real cost will continue to increase. An unmistakable consequence is that technologically:, advanced 
socicties must seek alternate fuel sources for generating power.

The only practicable alternatives to fossil fuels are nuclear sources, solar energy, and geothermal energy. The last two appear to be ruled out on economic grounds except for special local installations (Hottel 1975, Rose 1974). Conventional nuclear energy based on the fission of available high mass elements is a practicable alternative for the near term, but for the intermediate and long term only the breeder fission reactor and the fusion reactor offer realistic possibilities. A full scale demonstration plant for liquid metal fast breeding fission power generation is now under construction, but sharp escalations in the projected costs have led to increased concerns about the economic merit of this approach. On the other hand fusion power has not even been shown to be feasible.

Given the uncertainties about any of the alternative sources of energy and our general inability to predict breakthroughs, it would be premature and certalnly unisise lu cornmit national resources in a major way to a single solution to the energy problem to the exclusion of other possible solutions. But it would be equally unwise to rule out arbitrarily any bizarre possibilities unless the contrary evidence is unmistakable.

\section{Fnergy Needs and Available Fuels}

An important driving force for the expansion of nuclear power generation capability" is the declining availability of 


$\therefore-4-$

fossil fuels. Table 1. presents some data compiled from a variety of sources by Hafele (1974) on current and projected demands for energy and on the likely recoverable fuel resources.

Table 1。 Energy Consumption.

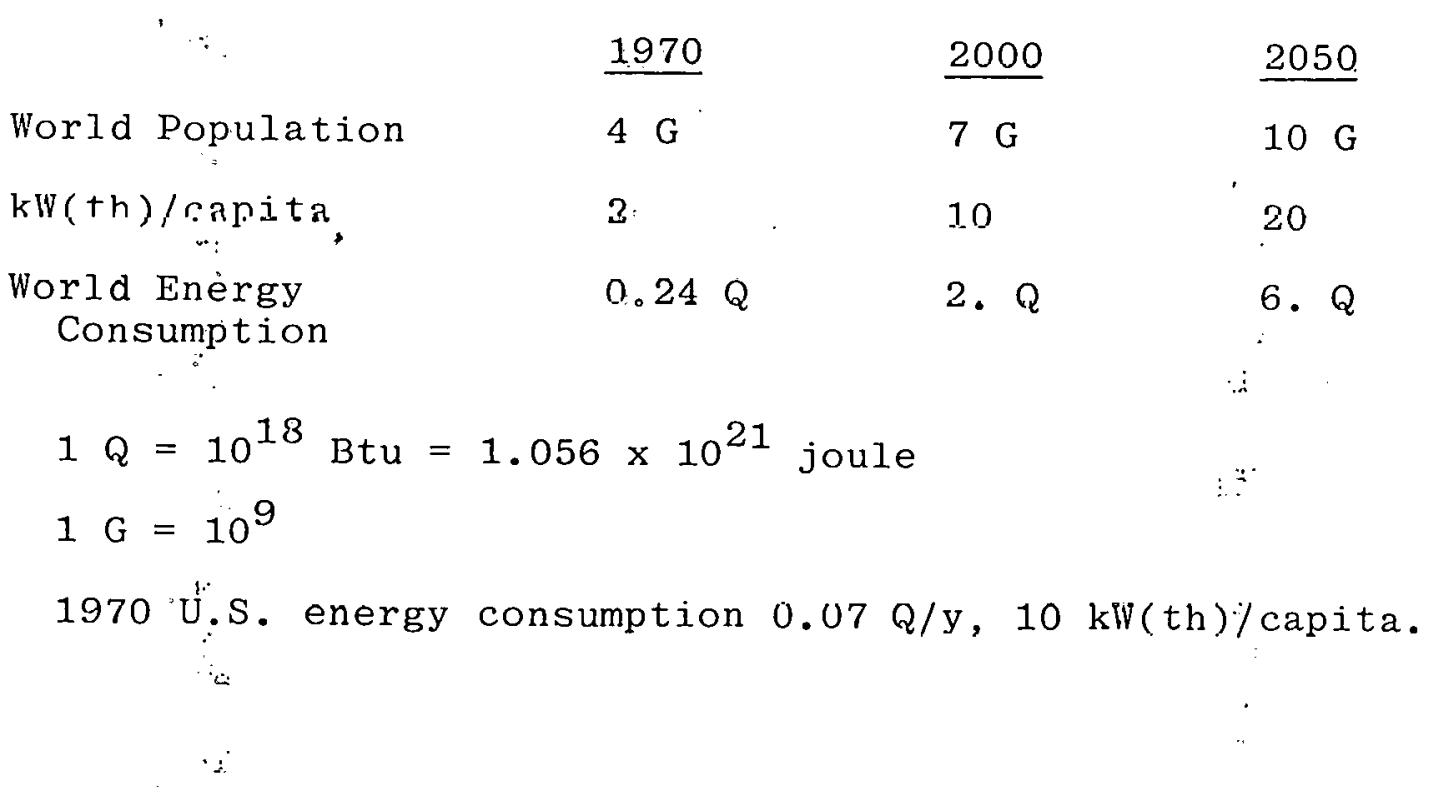

For solar energy the equivalent resurures in her year is 1,400 assuming the overall average solar energy deposition on the earth's surface is $90 \mathrm{w} / \mathrm{m}^{2}$. Thus if one per cent of the solar energy incident on one per cent of the earth's surface could be converted into useful energy, the contribution to the global energy supply would be: $0.14 \mathrm{Q}$.

The implications of the foregoing tables and comments are that coal and uranium will have to be relied on increasingly as primary energy srouces for the near term; for the longer term, uranium in breeder reactors, and lithium and deuterium in fusion reactors will have to be the principal 
Table 2. Fuel Resources (Energy Content in $Q$ )

\begin{tabular}{|c|c|c|}
\hline Source & Known Recoverable & Eventually Recoverable \\
\hline Coal & 17. 3 & 192 . \\
\hline Crude Oil & 1.7 & 11.1 \\
\hline Natural Gas & 2.0 & 10.1 \\
\hline Tar Sand Oil & 0.2 & 1.7 \\
\hline Shale Oil & 0.9 & 1.1 \\
\hline \multicolumn{3}{|l|}{ Uranium } \\
\hline$\$ 10 / 1 \mathrm{~b} \quad \mathrm{U}_{3} \mathrm{O}_{8}$ & $0.7 \quad(70)$ & $30 \quad(3,000)$ \\
\hline$\$ 100 / 1 b$ & & $200-1,000(20,000-100,000)$ \\
\hline Lithium (oceans) & & $7 \times 10^{5}$ \\
\hline Deuteriurn & & $3 \times 10^{8}$ \\
\hline
\end{tabular}

Note: The figures for uranium are based on 1968 dollars. The numbers in parentheses are for breeder reactors operating at energy conversions of $3.5 \times 1010 \mathrm{Btu}$ per $1 \mathrm{~b}$. $\mathrm{U}_{3} \mathrm{O}_{8}\left(8.1 \times 10^{13} \mathrm{~J}\right.$ per $\mathrm{kg}$ $\mathrm{U}_{3} \mathrm{O}_{8}$ ). The numbers without parentheses are for light water reactors at energy conversions of $3.5 \times 10^{8} \mathrm{Btu}$ per $1 \mathrm{~b} . \mathrm{U}_{3} \mathrm{O}_{8}\left(8.1 \times 10^{11} \mathrm{~J}\right.$ per $\mathrm{kg} \mathrm{U}_{3} \mathrm{O}_{8}$ ). 
fuels with possibly some assistance coming from solar sources.

\section{Historical Background}

A: brief account of the history of the development of fusion power will provide a perspective on some of the important problems and perrhaps provide some clues as to the likcly time table for the emergence of the first...cumuleid plant.

In the waning days of World War II a classified, theoretical effort under the code name Project Matterhorn was initiated at Princeton to explore the possibility of constructing a hydrogen bomb, i.e., nuclear weapon based on the fusion of: low-Z elements rather than the fission of unstable high-z elements. The theoretical feasibility of the hydrogen bomb was demonstrated fairly handily, and the project was transferred to Los Alamos for the actual construction of the boinb.

Lyman Spitzer, an astrophysicist participating in Project Matterhorn, suggested that the fusion reactions involved in the hydrogen bomb might be carried out under controlled conditions such that a steady production of electric power would result. Based on this suggestion the first conceptual design of a fusion power reactor system was undertaken. The resulting design report, called the Model $D$ Stellarator Report (because it envisaged a development program involving three scaling models before the commercial 
prototype), was a surprisingly prescient document, which anticipated most of the problems encountered so far (Spitzer et al 1954).

In company with current thinking about the likely characteristics of fusion power machines, the Model D machine was visualized as a large, doughnut-shaped vacuum bottle surrounded by a blanket filled with liquid lithium and liquid water, in turn surrounded by great magnet coils. Inside the reactor fully ionized atoms of deuterium and tritium at temperatures in excess of $10^{8} \mathrm{~K}$, constrained by magnetic fields of 50 kgauss or more to prevent impingement on the reactor walls, fused to form helium and give off energy largely in the form of fast neutrons. The neutrons and their energies were captured in the blanket, and additional. energy was produced there by the transmutation of lithium to tritium and more helium.

Essentially all the energy picked up by the blanket was manifested as sensible heat in the liquid lithium and the moderator water. These streams were circulated through conventional boilers to generate steam for driving conventional turbogenerators to produce electricity.

The reactor was fed by injecting a steady stream of solid pellets of equimolar deuterium and tritium, the deuterium purchased from the outside, the tritum recovered continuously from the breeder lithium.

Since only a few per cent of the feed reacted per pass through the reactor, a gas rate some twenty times the burnup 
rate had to be circulated through the reactor. To assist this circulation two large chambers (divertors) with appropriately shaped magnetic fields were inserted at two points in the reactor to skim off and feed to vacuum pumps any ions that diffused to the walls of the reactor. The circulated inaterial went through the whole temperature spectrum from plasma. (i。e. fully ionized gas) at $10^{8} \mathrm{~K}$ to solid at a few $\mathrm{K}$.

The Model D Report recognized that the plasma physics problems would probably be the most difficult of solution. There was no first hand knowledge of the properties of plasmas at high temperatures; what little knowledge existed had largely been inferired from the behavior of stars like the sun. As a consequence the initial activity in the fusion program was focussed exclusively on plasma physics. Unfortunately the problems proved to be so difficult that today, after more than two decades of continually expanding effort, the principal activity in the program is still concerned with plasma physics. The first research facility in the field:-was the Princeton Plasma physics Laboratory, and today it: is the largest fusion facility in the United States and the only large one on a university campus. There are other large installations now at the Oak Ridge lvational Laboratory, at the Los Alamos Scientific Laboratory; at the Lawrence Livermore Laboratory,' and in Europe and Japan. Many other laboratories in this country have growing activities in fusion.

At the outset all of the support for the program came from the Atomic Energy Commission, now the Energy Research and 
i. Bevelopment Administration (ERDA), but now an increasing volume of support is coming from the private utilities through the Electric Power Research Institute (EPRI) and other industrial sources, and work in laser fusion is supported to some extent by the Department of Defense.

The current budget of the Divison of Controlled Thermonuclear Research (DCTR) of ERDA exceeds \$120 million, and if the objective of a demonstration power plani by the late 1990s is to be achieved the budget will have to escalate markedly.

\section{Plasma Physics}

It is beyond the scope of this review to describe in detail the problems of plasma physics, but some features of these problems dictate important characteristics of the power machines and hence many of the technological problems.

Although a very large number of fusion reactions are known, only a very few have a useful potential for power generation. Table 3, adapted from Post and Ribe (1974), lists the most attractive of these reactions together with the chemical reaction for the oxidation of hydrogen to provide a comparison of the energies involved. 
Table 3。 Typical Fusion Reactions

$$
\begin{aligned}
& \mathrm{D}+\mathrm{T} \rightarrow{ }^{4} \mathrm{He}+\mathrm{n}+17.58 \mathrm{MeV}(94,000 \mathrm{kWh} / \mathrm{g}) \\
& \mathrm{D}+\mathrm{D}+{ }^{3} \mathrm{He}+\mathrm{n}+3.27 \\
& \mathrm{D}+\mathrm{D} \rightarrow \mathrm{T}+\mathrm{p}+4.04 \\
& \mathrm{D}+{ }^{3} \mathrm{He}+{ }^{4} \mathrm{He}+\mathrm{p}+18.34 \\
& \mathrm{~T}+\mathrm{T} \rightarrow{ }^{1} \mathrm{He}+2 \mathrm{n}+11.32 \\
& \mathrm{H} 2+\frac{1}{2} \mathrm{O}_{2} \rightarrow \mathrm{H}_{2} \mathrm{O}+3 \times 10^{-6} \mathrm{MeV}(0.039 \mathrm{kWh} / \mathrm{g})
\end{aligned}
$$

In this table $\mathrm{n}$ stands for neutron, $\mathrm{p}$, proton, is the hydrogen isotope of mass $1, \mathrm{D}$, deuterium, the isotópe of mass 2 , and $T$, tritium, the isotope of mass 3. The reaction energies are given in millions of electron volts per event and in kilowatt hours per gram.

'lhe fusion reaction rate is given by

$$
\mathrm{R}=\mathrm{n}_{1} \mathrm{n}_{2}(\overline{\sigma \mathrm{V}})
$$

where $\mathrm{R}=$ number of fusion events $/ \mathrm{cm}^{3} \mathrm{~s}$ 。

$$
\mathrm{n}_{\mathrm{i}} \quad=\text { number density of ion } \mathrm{i}, \mathrm{cm}^{-3}
$$

$\overline{\sigma v}=$ product of the cross section for the reaction and the relative velocity of the ion averaged over the velocity. distribution 
$\sigma=$ cross section for the reaction, number of fusion events / number of incident particles times number of target nuclei per $\mathrm{cm}^{2}$

$$
\mathrm{v}=\text { particle velocity. }
$$

The bar indicates that the product of the cross section and ion, velocity is averaged over the velocity distribution.

At high temperatures the gas law applies and

$$
\mathrm{n}_{\mathrm{i}} \quad=\mathrm{P} / \mathrm{kT}
$$

where $\mathrm{P}=$ total pressure

$$
\begin{aligned}
& \mathrm{T} \quad=\text { absolute temperature } \\
& \vdots_{\mathbf{k}} \quad=\text { Boltzmann constant }
\end{aligned}
$$

Thus from Eq. (7) and Eq. (8) for any given maximum pressure, as might be dictated by magnetic and other constraints the reaction rate will be proportional to $\overline{\sigma v} / T^{2}$. Figure 1., adapted from Mills (1972), shows a plot of this function, normalized as a relative power output density, versus temperature for the fusion reactions listed in Table 3 . The plot for the $D-D$ reactions is an average for the two $D-D$ reactions. 


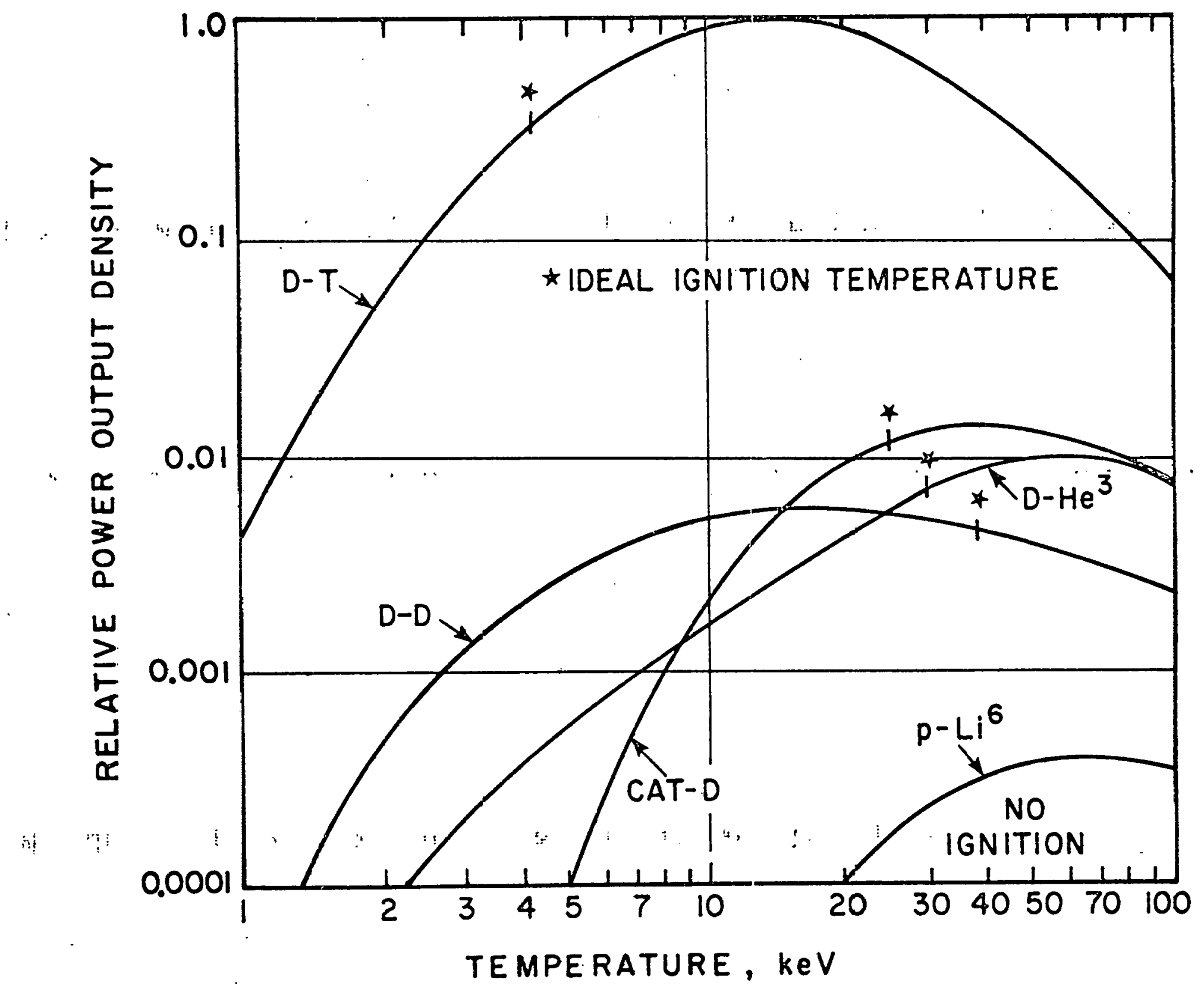

714222

Figure I. Normalized Output Power Density for Various

Fusion Fuels as a Function of Plasma Temperature. 
The temperature scale on the figure is given in $\mathrm{keV}$, which is a common mode of expression in plasma physics. It is actually an ion energy. The corresponding temperature in kelvin may be obtained from the fact that the Boltzmann constant in $\mathrm{eV} / \mathrm{K}$ is $0.86170 \times 10^{-4}$. Thus $10 \mathrm{keV}$ is approximately $10^{8} \mathrm{~K}$.

The vertical bars on the reaction rate curves are the estimated ignited points for the various reactions, i.e., the lowest temperature for which the energy release to the charged particles is equal to the bremsstrahlung radiation losses (the principal mode of energy loss from the charged particles)。 From the, standpoints of ignition temperature and rate of reaction the $D-T$ reaction is clearly superior to any of the other reactions. As a consequence virtually all of the fusion research effort has been based on the assumption that this reaction would be the first one used for commercial power generation.

From available data on fusion reaction cross sections and energy release rates it is possible to specify the plasma conditions requisite to the generation of power. The most commonly used specification of these conditions is the Lawson Criterion, which states that the product of the ion density, $\mathrm{n}_{i}$, and the reaction time, $\tau$, for the $\mathrm{D}-\mathrm{T}$ reaction at typical temperatures like $10^{8} \mathrm{~K}$ must exceed $10^{14}$, i.e. $\mathrm{n}_{i}{ }^{\tau}>10^{14} \mathrm{~s} \mathrm{~cm}^{-3}$. This result was obtained by Lawson (1957) by a straightforward energy balance on a system of $n_{i}$ ions at $T K$ for $\tau$ seconds assuming the energy release is converted to 
electricity at an cfficiency of one-third and used to preheat the fuel and sustain the radiation losses. A more realistic analysis by Mills (1971) is based on an energy balance around a steady-state machine and assuming that only the energy release to the charged particles must support the heating of the fuel and the brensstrahlung radiation losses. The result is a closed contour on the $n_{i} \tau-T^{-}$plane with a typical lower, value at $10^{8} \mathrm{~K}$ of $5 \times 10^{14} \mathrm{~s} \mathrm{~cm}^{-3}$ for $\mathrm{n}_{i}{ }^{\tau}$.

Since the temperature is essentially fixed by the Ignition requarement, only the 'ion density and the confinement time can. be traded off against each other. ... That is, confinement time may be short if the ion density is high enough and vice versa.

Fùsion can be accomplished at high densities by deposition of energy into a condensed mass nf deuterium and tritium rapidly enough so that the ignition temperature is reached before the ions have a chance to fly apart. The principle here is inertial confinement, since it is the inertia of the fuel mass that provides the confinement. The hydrogen bomb employs this principle, using a fission bomb as the energy source.

The idea of using successions of hydrogen bomb explosions: for example in salt caves, as a means of generating power has been studied under the code name Pacer (Hubbard et al 1974), but the project is moribund. The principal current effort in inertially confüned fusion systems for power generation is laser driven fusion. The idea here is to focus 
highly energetic, symmetrically deployed laser beams on a small pellet of fusible fuel mixture under such conditions that the pellet will implode and quickly reach ignition temperatures.'

It is conceivable that controlled fusion will first be demonstrated in a laser driven device, but the problems of achieving a reliable, essentially continuous power generator from a mini-bomb machine seem enormously difficult.

The alternative to using inertial confinement is to employ forces that act at a distance and try to run under nearly steady state conditions rather than shocked conditions. The only forces that act a distance are gravitational forces, magnetic fields and electrical fields. Gravitational fields work, as the sun and other stars attest, but the scale is too large. Electrical fields cannot be devised to confine charged particles practicably. Magnetic fields, however, can readily contain charged particles, and by adroit arrangement of field windings can produce virtually any desired shape of containment.

At readily attainable fields of the order of 100 kilogauss, ion densities of $10^{14}$ can be achieved at temperatures of $10^{8} \mathrm{~K}$. Under these conditions the Lawson Criterion requires that the containment time be of the order of $0.5 \mathrm{~s}$. Essentially all of the fusion research of the past twenty years has been concerned with the problems of getting a gas heated to a temperature of $10^{8} \mathrm{~K}$ at a density of $10^{14} \mathrm{~cm}^{-3}$ and holding it there for an appreciable fraction of a second. Two of the three conditions have been achieved simultaneously 
but not all three. At the high temperatures obtaining in the reactors the gases become fully ionized, and their behavior in magnetic fields though subscribing in principle to Maxwellian physics have proved sufficiently bizarre to warrant calling them plasmäs and considering them a fourth state of matter.

Three basic devices for magnetic confinement have been employed and are still under study, viz. mirrors, theta pinches, and tokamaks. Mirror machines, in their simplest articulation, are straight tubular reactors with high concentrations of magnetic fieids at the ends of the tube to prevent escape of the ions to the outside by reflecting them back into the tube, hence the name mirror. Theta pinch machines comprise a toroidal reactor with an aspect ratio akin to that of a bicycle tire. They are operated in a strongly pulsed mode in that the reactor is charged with fuel, subjected to the magnetic field and then pumped out, and the cycle is then repeated. Tokanaks (the word is a Russian acronym for a magnetically confined, toroidal reactor) have toroidal reactors' with relative dimensions like those of a doughnut. They are quasi-steady-state devices with continuous feed and pumpout.

of the three machines the tokamaks appear to offer the greatest promise of success, and the preponderance of current research on magnetically confined plasmas make use of the tokamak principle. This principle promotes the stability of the plasma by inducing a strong direct current in the plasma itself. Prior to the introduction of this principle the approach to achieving fusion conditions in plasmas had been 
sẹriously restricted by the onset of unstable gross motions in the plasma, leading to losses of charged particles to the reactor walls and resultant cooling.

Another problem with magnetically confined plasmas is the inevitable diffusion of the charged particles across the magnetic force lines to the walls. The simple solution to this problem is to make the minor radius of the reactor large enough so that the diffusion time is of the same order of magnitude as the desired confinement time. An unfortunate implication of this solution is that the minor radius of the reactor cannot be less than a meter. Thus the demonstration of the feasibility of magnetically confined fusion requires a large and hence expensive experimental device.

For this demonstration there is now under construction at the Princeton Plasma Physics Laboratory a tokamak fusion test reactor (TFTR). Scheduled for completion shortly after 1980, it will be the largest fusion test facility in the world and the first one to attempt the fusion of deuterium and tritium. The reactor vessel has an inner minor radius of $1.1 \mathrm{~m}$ and a major radius of $2.65 \mathrm{~m}$. It will be operated in a pulsed mode in which a relatively cool plasma of tritium ions in the reactor is bombarded by a neutral beam of highly energetic deuterium atoms (Dawson et al 1971). Although the device will not be a net power producer, it should convincingly demonstrate that fusion can be carried out under controlled conditions and that the basic plasma physics is sufficiently well understood to assure scaling up to an experimental power reactor. The 
estimated price tag for this inslallation at the time of its design was $\$ 215$ million.

\section{Fusion Development Program}

Research and development for fusion power in the United States is funded almost entirely by the Division of Magnetic Fusion Energy (DMFE) of the Energy Research and Development Administration (ERDA). As a basis for structuring and organizing its program,the DMFE has identified five major program milestones (Kintner 1976). The first is to demonstrate reactor-like conditions in hydrogen plasmas by 1977-1979. A principal instrument for this demonstration is the Princeton Large Torus (PLT) now involved in experiments at the Princeton Plasma Physics Laboratory.

The second milestone is the actual burning of deuterium and tritium with pulsed injection heating in the TFTR described above. This device is to be in operation by 1981 .

The third milestone is the successful operation of an experimental power reactor (EPR-I) by 1985 generating several tens of magawatts of electric power.

Next is the operation of a second experimental power reactor by. 1990 generating perhaps $100 \mathrm{MW}(\mathrm{e})$. 'l'he Iitth and final milestone is the operation of a demonstration power plant by 1995-1997 to ascertain overall reliability and economy. This unit might generate power at the $500 \mathrm{MW}(\mathrm{e})$ or higher levels. 
Fusion development efforts in other countries are geared to about the same timetable with the exception that some intermediate steps may be skipped by taking advantage of the results of experiments here.

Although the proposed program in this country is not an emergency crash program, it is an aggressive one that will require a continuing escalation of budget from the current annual rate of about $\$ 120$ million. Whether the actual program can adhere to the proposed timetable, of course, will depend on how well the plasma physics problems can be handled. To gauge the latter we will make use of conceptual plant designs.

\section{Conceptual Designs}

In the development of a novel engineering device like a fusion power reactor, it is desirable to preserve a wide spectrum of. options in the early stages of the development to avoid cutting off alternatives which in the long run might prove to be advantageous. At the same time, however, it is desirable to undertake studies aimed at providing hard-headed engineering perspectives on designs achievable with existing, or nearly so, technology. These designs provide benchmarks for appraising more sjeculative possibilities.

As a result of growing confidence in the likelihood of developing practicable ways of controlling fusion reactions for the generation of electric power, a number of laboratories have undertaken designs of hypothetical fusion power plants to 
provide useful references for gauging conceptualimprovements. By exposîng areas of uncertainty these designs also provide guidance for experimental and devlopment programs. '

In addition to the pioneering Model D Stellarator design previously mentioned there have been close to twenty other conceptual designs described in the literature. Most of these have been concerned with particular physical or physical or technological problems and hence have not addressed the full spectrum of constraints that must be accommodated in a complete power beritralur. A guod summury of the reatures of nine differcnt designs employing tokamak reactors is presented by Fraas (1975) in a detailed comparison of systems proposed by fusion groups at Oak Ridge, Brookhaven, Princeton, Wisconsin (Madison), Culham, Frascati, Julich, and Japan (Tokai). This study affords a good overview of the structural and materials problems involved in fusion power development. Davis and Kulcinski (1976) present a detailed parameter comparison of nineteen proposed designs for $\mathrm{D}-\mathrm{T}$ tokamak fusion reactor including four near-term (through 1985) test reactors, five mid-term (through 1990) reactors, and ten long range (through 2020) power reactors. Their comparison takes account of plasma parameters and characteristics of blankets, shields, neutronics; tritium handling, materials, magnets, power cycles, resources, and economics.

Conceptual designs are described by Peterson et al (1974) for" a mirror machine and by Burnett et al (1972) for a theta pincï machine. 
Although the reactor schemes in these designs are quite disparate, much of the overall power systems have common features. For most of the systems the power generating equipment, .comprising boilers and turbo-compressors, is conventional. Furthermore, since most of the energy produced by the fusion reactions resides in energetic neutrons, all of the power systems must incorporate blankets to capture the neutrons. For D-T fuel cycle machines, these blankets serve essentially the same purposes regardless of the particular reactor scheme, but the designs proposed for them are almost as disparate as the reactors themselves.

The conceptual design we shall use for examining the full range of chemical engineering problems is the Princeton Reference Design Model, an hypothetical tokamak system requiring no new technology for its construction.

Princeton Reference Design (PRD)

The essential characteristics of the Princeton model are presented in Table 4 and a cutaway drawing it shown in Fig. 2. and a cross-sectional view in Fig. 3. A detailed description of this plant is presented in a 600-page design report prepared by some sixteen scientists and edited by Mills (1974).

In this machine, deuterium and tritium in the form of small frozen pellets are injected continuously into a tokamak reactor, Nearly $10 \%$ of the fuel ions fuse at the conditions 


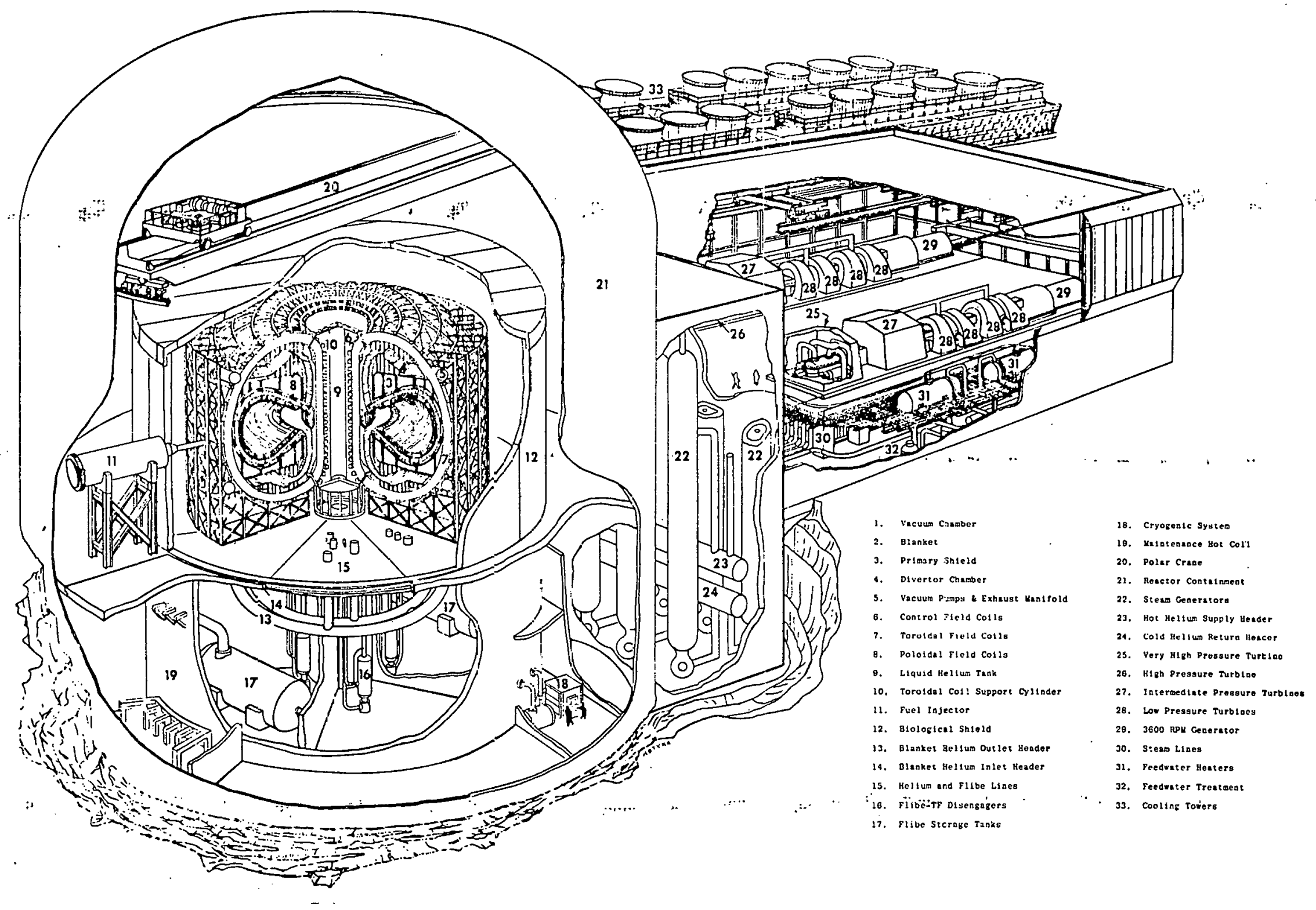

Figure 2. Cutaway Sketch of Princeton Reference $\begin{array}{r}744301 \\ \text { Design. }\end{array}$ 


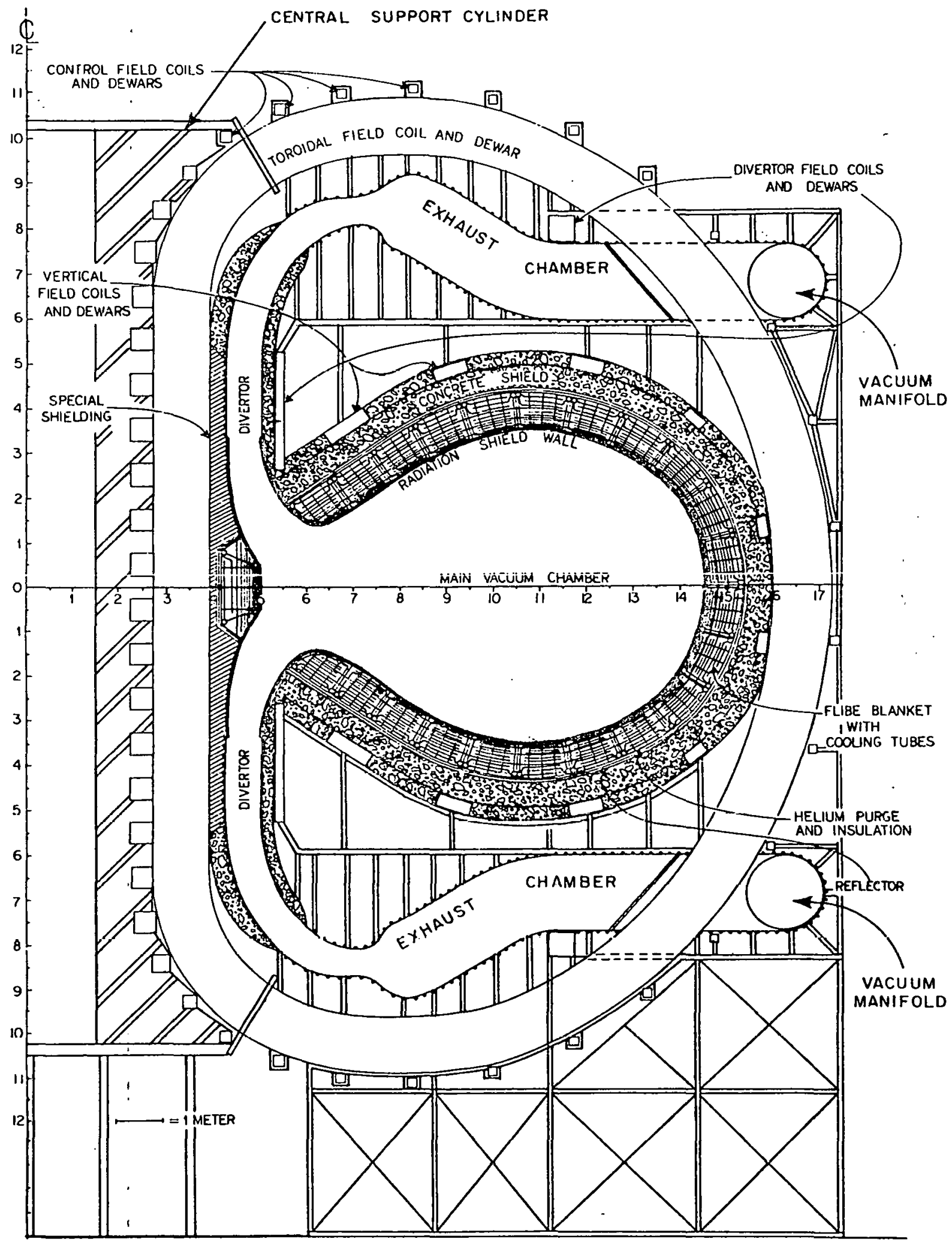

744378

' Flgure 3. Reactor Cross bection (one-half). 
prevailing in the reactor, and the resulting fast neutrons are captured in a blanket consisting of a molten mixture of lithium fluoride and beryllium fluoride, cooling tubes containing helium gas as coolant, and structural members.

The principal fusion reactions are

$$
\mathrm{D}+\mathrm{T} \rightarrow \mathrm{n}+\mathrm{He}+17.58 \mathrm{MeV}
$$

and the principal capture and neutron multiplication " reactions are

$$
\begin{aligned}
& \mathrm{Li}^{7}+\mathrm{n} \rightarrow \mathrm{T}+\mathrm{He}+\mathrm{n}-2.47 \mathrm{MeV} \\
& \mathrm{Li}^{6}+\mathrm{n} \rightarrow \mathrm{T}+\mathrm{He}+4.78 \mathrm{MeV} \\
& \mathrm{Be}^{9}+\mathrm{n} \rightarrow 2 \mathrm{He}+2 \mathrm{n}-1.58 \mathrm{MeV}
\end{aligned}
$$

Since the transmutation of 1 ithium-6 as given by Eq. (10) is the preponderant fusion reaction in the blanket, the nuclear energy release from reactions in the blanket compriscs a large fraction, nearly one-fifth, of the total energy generation in the plant.

In the PRD all of the energy release is colilected as sensible heat in circulating helium gas compressed to $50 \mathrm{~atm}$ ( $\left.5 \mathrm{lN} / \mathrm{m}^{2}\right)$. The breeder salt, comprising a 48-52 molar mixture of lithium fluoride and beryllium fluoride (flibe) is also 
Table 4. Some Characteristics of the Princeton Reference Design Fusion Power Plant

Reactor

Magnetic Field

a) At nominal center line of plasma ( $R=10,5 \mathrm{~m}) \quad 60$ kilogauss

b) Maximum, at inside conductor $160 \mathrm{kilogauss}$

Plasma

Confinement Time Vol ume

$3.8 \mathrm{sec}$ $2190 \mathrm{~m}^{3}$

Percent Burnup per Pass

$8.7 \%$

Total Reaction Rate

Daily Fulel Consumption

a) $\mathrm{D}_{2}$

b) $\mathrm{T}_{2}$.

$0.352 \mathrm{~kg}$

$0.527 \mathrm{~kg}$

Tritium Feed Rate

$4.545 \mathrm{~kg} / \mathrm{day}$

Fuel Pellets

$1 \mathrm{~mm}$ DT ice pellet with argon core to produce 1.8 atom percent argon in plasma

Burn Period per Cycle $100 \mathrm{~min}$

Shutdown Period per Cycle

3 min

\section{Breeding Blanket}

Thickness

$74 \mathrm{~cm}$

Daily Fuel Consumption
a) $\mathrm{Li}^{6}$
b) $\mathrm{Li}^{7}$
c) $\mathrm{Be}^{9}$

$1.011 \mathrm{~kg}$

$0.091 \mathrm{~kg}$

$0.362 \mathrm{~kg}$ 

Breeding Fluid
Volume (in blanket)
Mass (in blanket)
Circulation Rate

Net Breeding Ratio eutectic flibe
$48 \mathrm{LiF}-52 \mathrm{BeF}_{2}$

$962 \mathrm{~m}^{3}$

$1.86 \times 10^{6} \mathrm{~kg}$

$4.0 \times 10^{6} \mathrm{~kg} / \mathrm{hr}$

1.10

$5305 \mathrm{MW}$

$5250 \mathrm{MN}$

2407 MW

2030 MW

$38.3 \%$

$2.75 \mathrm{~kg}$

Tritium Tnventory

Locations

a) Primary Fuel Loop

b) Salt Processing Loop: dissolved in salt

c) Cooling Helium: contained in coolant recovery system

d) Secondary Containment, Walls, etc.

e) Reserve for Startup
$.50 \mathrm{~kg}$

$.01 \mathrm{~kg}$

$.10 \mathrm{~kg}$

$.01 \mathrm{~kg}$

$\because 10 \mathrm{~kg}$

$.03 \mathrm{~kg}$

$2.00 \mathrm{~kg}$ 
circulated continuously, but it is not cooled. Its circulation rate is fixed to permit desorption of the tritium and helium gases formed from the breeding reactions. This rate suffices to prevent excessive temperature rises in the salt while it is in the blanket.

The coolant helium flows through conventional heat exchangers, which generate high pressure steam to drive turbogenerators for electric power production.

With the above brief description as a base let us look in some detail at the various parts of the plant where there are important chemical engineering problems.

Primary Fuel Loop

An overall perspective on the fuel flows is presented in Fig. 4., which shows the three circulating loops principally involved in fuel handling. The coolant helium loop is included because there is a finite transport of tritium into the helium at many points in the cooling circuit by virtue of the permeation of metal walls at high temperatures. The elements of the primary fuel loop itself are shown in greater detail in Fig. 5 .

Since this loop contains the reactor, the critical problems here are those of plasma physics. Almost as critical, however, is the problem of feeding the fuel into the reactor.

For quasi-steady-state machines like the PRD the fuel must. he fed continuously either as a stream of pellets or 


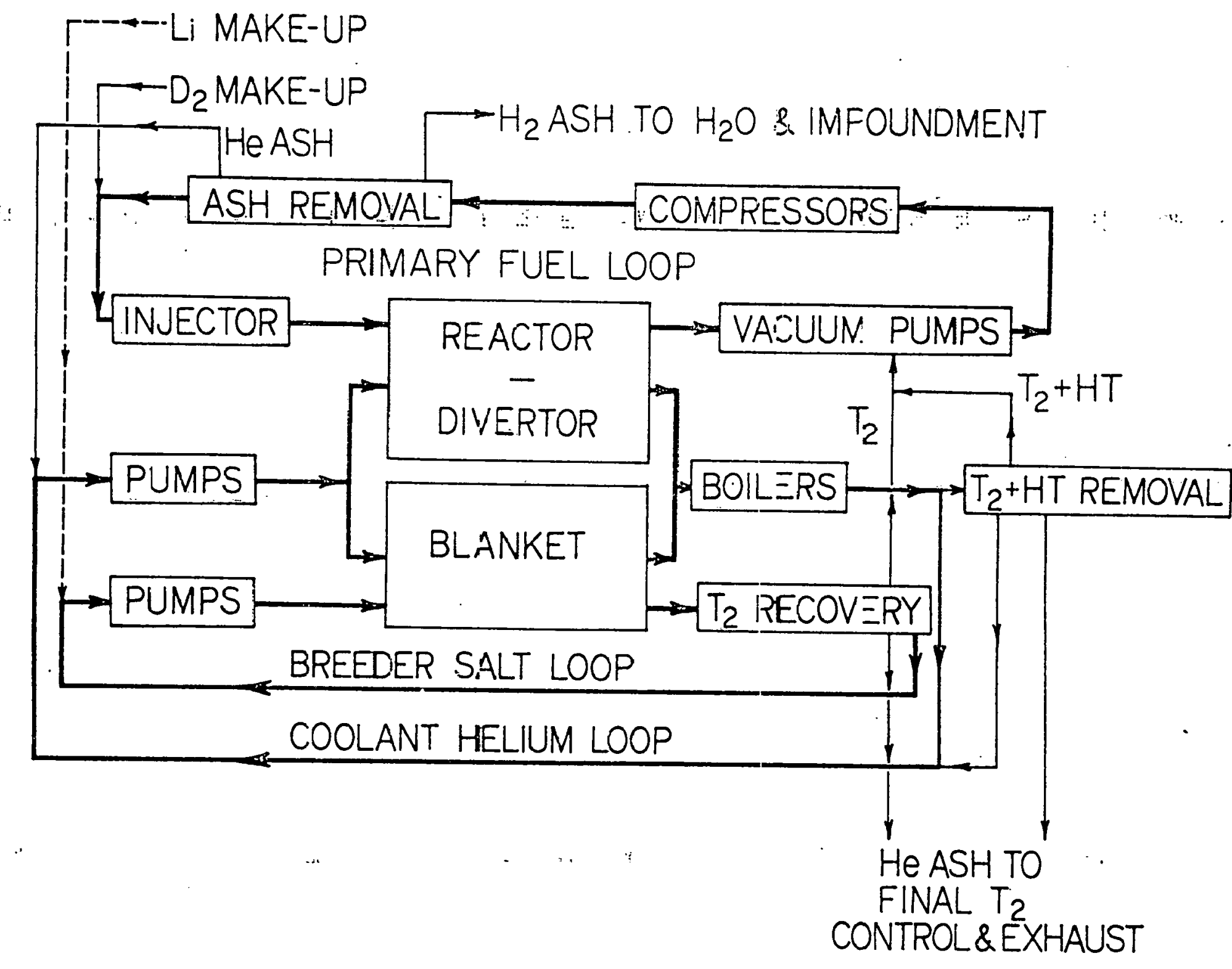

Figure 4. Principal Fuel Flows. 


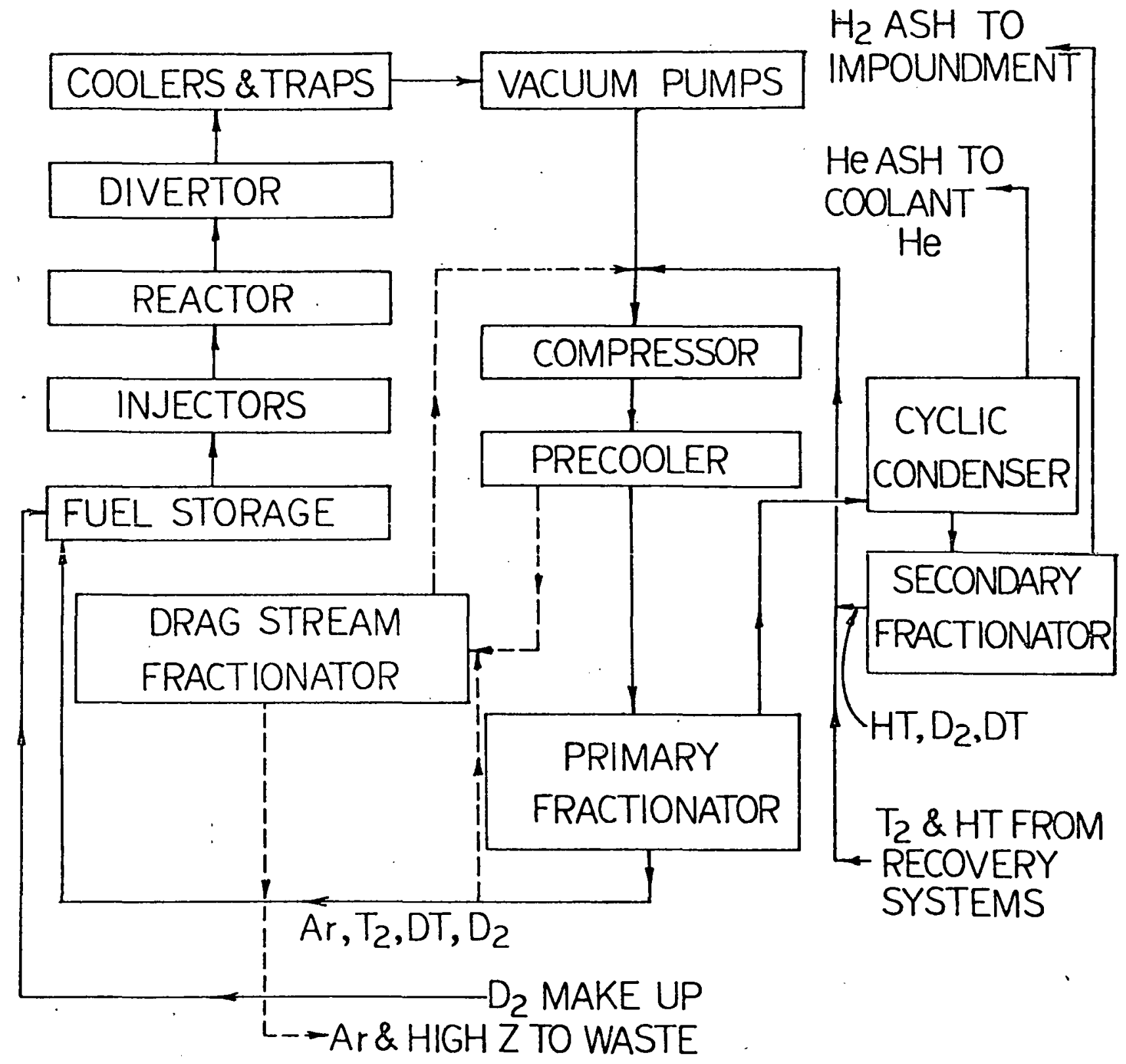

744396

Figure 5. Primary Fuel Loop. 
droplets or as an. energetic beam of neutral atoms. As mentioned èarlier the TFTR will employ neutral beam injection, but this mode of feeding requires large amounts of electrical energy and probably could never be econornic for a fusion power reactor.

The PRD uses solid pellet injection (Gralnick 1974) wherein frözen droplets approximately $1 \mathrm{~mm}$ in diameter are accelerated electrostaticallv to velocities in exress of $10^{4} \mathrm{~m} / \mathrm{s}$ ànd ted through some 40 injectors distributed about the reactor a.t a total rate of abuul 300 pellets/s.s. High velocities are necessary to ensure that the pellets penetrate deeply into the plasma before they evaporate and become immobilized by the magnetic field as they ionize. C. D。 Hendricks "(Gralnick 1974) has demonstrated that solid droplets can be accelerated to these high velocities, but there are large areas of ignorance in this problem, and relatively little effort is focussed on it.

In the reactor the ions circulate for over three seconds before diffusing out toward the walls where they are continuously skimmed off by the divertors. In that time nearly ten per cent of the deuterium and tritium fuel ions fuse. The ions entering the divertors are cooled by contact with cold particles änd with cooled metal surfaces. 'l'hcy récombine to molecules and after further cooling are pumped out by mercury diffusion pumps.

Bombardment of the divertor surfaces and to a lesser extent the reactor walls by energetic ions results in some ions 
implantation in the metal. Since the temperatures of most of these metal surfaces exceeds $300^{\circ} \mathrm{C}$, the hydrogenic species (mostly deuteriurn and tritium, but also small amounts of protium) will tend to diffuse through the metal walls and enter the coolant helium. The more energetic ions will also tend to sputter off metal atoms, which in the reactor can result in excessive cooling and possibly quenching of the fusion reactions.

More serious than the effects of the ions, however, are the effects of the neutron flux through the first wall of the reactor. Indeed, many in the fusion scientific community regard the first wall problem as second only to the plasma physics in difficulty and challenge (Kulcinski 1976).

Although the metals suggested as candidates for the first walls of fusion reactors are relatively transparent to neutrons, the fluxes in fusion power reactors are so high $\left(10^{19} / \mathrm{m}^{2} \mathrm{~s}\right.$ for the $\left.\mathrm{PRD}\right)$, that every atom in the metal lattice of the first wall is estimated to undergo 10 to 30 displacements per year. Depending on the thickness and nature of the first wall as much as 5 per cent of the total energy production of the machine can be deposited there with the result that special cooling and thermal stress problems must be accommodated。

Since the PRD is designed to use available technology, the principal material of construction used for the vacuum wall of the reactor and for piping and structural elements within the blanket is the Wiggins alloy Nimonic PE-16, a high nickel, 
austenitic alloy. Other materials suggested for this exacting duty include other stainless steels, and refractory metals like molybdenum; vanadium and niobium and related alloys.

For systems using liquid lithium as the breeding medium the refractory alloy of niobium containing one per cent zirconium, $: \mathrm{Jb}-1 \mathrm{Zr}$, has many attractive properties, not the least of which is that it can withstand temperatures in excess of $1000^{\circ}$ C (Fra.a.s 1.973).

It: is clear that the materials problems are particularly severe within the reactor - blanket region. Intense radiation, steep thermal gradients, corrosive attack by breeder fluids, need for maximum temperatures to achieve high thermodynamic efficiency, all combine to constrain narrowly the range of practicable choices. Only detailed and costly experimentation can identify the ultimate materials.

A detailed accounting of current researches is given in the first "two volumes of the proceedings of the International Conference, on Radiation Effects and Tritium Technology for Fusion Reactors held in Gatlinburg, Tennessee in October 1975 (Watson and Wiftéen, editors, 1976).

\section{Primary Fuel Processing}

The gases exhausting from the divertors via the vacuum pumps contain mostly deuterium and tritum plus a few per cent each of helium and argon and something less. than a per cent of ordinary hydrogen (protium)。Argon is added to the PRD feed to 
prevent excessive escalation of electron temperatures in the reactor. Its presence complicates slightly the processing of the primary fuel loop gases.

Since the reactor feed must be injected under cryogenic conditions, the simplest strategy for purifying the recycle gas is to make use of cryogenic fractional distillation. By using small packed columns with separating powers equivalent to 50 theoretical plates and operating them at essentially total reflux, it is possible to eliminate the helium and protium ash. Some of the protium is present initially as $\mathrm{TH}$, and consequently catalyzed equilibration is necessary to ensure the separation of the protium from the tritium. The scale of all operations here is small, but there are no basic difficulties since the volatilities of the various isotopic compounds are well spread out. Experimental studies at the Mound Laboratory confirm the practicability of cryogenic fractional distillation (Wilkes' 1975). A typical arrangement of process elements is shown in Fig. 5 .

An alternative method that has been proposed for processing the primary fuel loop is multistage permeation. This method easily separates the helium and argon from the hydrogen isotopes, and theoretically it should separate the $D$, $T$ and $H$ since the permeation proceeds atomically and the respective rates should go inversely with the atomic mass. The latter separation has not been demonstrated practicably, and it is possible that surface phenomena participating in the overall transport may confound the separability provided by the metal membrane alone. 
Blanket Characteristics

$v$

In a typical fusion power machine the blanket surrounding the reactor plays a number of important roles. First, it: must be a tritium breeder, capturing enough of the neutrons leaving the reactor to ensure a favorable breeding ratio for tritium; second, it must be a shield for the magnets, protecting them from neutrons and radiations whirh could cauce darnage or impose excessive heating loads on the cryogenic system which cools the magnets; and third, it must provide for the transfer to the power generating elements of the bulk of the energy produced by the fusion reactions. For inherently pulsed or cyclic devices like tokamaks, the blanket with its necessarily large thermal capacitance should also serve to provide most of the thermal ballast in the system so that the net energy flow to the power grid is at constant rate despite the filuctuating cnergy flow from the reactor.

Choice of Blanket Fluids

In early conceptual designs of fusion power reactors, there was a common tendency to choose a single fluid to fulfill in large measure all the funclions of like blanket. For example, the earliest conceptual design, the Model $D$ Stellarator, proposed the use of liquid lithium metal as breeder, coolant and principal shielding material. Subsequently, in part stimulated by a concern for the 
practicability of pumping an electric conductor through magnetic fields, a number of blanket schemes were proposed with molten salts as the principal multi-purpose blanket fluid. One of the earliest of these schemes (Johnson 1957) suggested the use of molten lithium nitrate or nitrite or mixtures thereof and slurries of lithium oxide crystals in these molten salts to increase the lithium density in the blanket. The cheap alkali nitrates and nitrites (those of sodium and potassium) have long had practical use as heat transfer media in the chemical process industries. In this use they have proved chemically and thermally stable up to moderately high temperatures and non-corrosive toward mild steels. As blanket fluids, the corresponding lithium salts would have the advantage that any tritium bred in them would be tightly bound up as water and readily recoverable as such.

Unfortunately the moderately high temperature achievable with the nitrates and nitrites are $10 \mathrm{w}\left(500^{\circ} \mathrm{C}\right.$ maximum) by power plant standards, and because the anions contain covalent linkages it is likely that these salts would be unstable toward neutronic bombardment. Consequently virtually all subsequent proposals of molten salts for blanket fluids involve mixtures of lithium fluoride and beryllium fluoridè (Homeyer 1965, Grimes and Cantor 1972).

The choice of blanket fluid is severely constrained. Stability in high neutron fluxes and other radiation and at high temperatures, freedom from adverse neutron capture reactions, and inertness toward bounding walls and structural 
materials are required of all fluids. In addition, for breeding fluids high lithium densities and easy tritium recovery are necessary. For coolants the thermal properties and flow properties (including electrical conductivity since flows across magnetic lines are unavoidable) must be favorable. If the plant is constructed using current fabrication technology, the principal material of construction for the blanket will most probably have to be austenitic otcel alleys. For these materials it is likely that higher average operating temperatures can be malntalned without excessive corrosive attack on metal walls if molten fluorides are emploỳed as the lithium-bearing breeder rather than liquid lithium. This temperature advantage, which exceeds $100^{\circ} \mathrm{C}$, with corresponding advantage in thermodynamic efficiency, coupled with the ease of tritium recovery from molten salts, led to the choice of molten fluorides as the breeding medium for the PRD. An additional factor was. the wealth of stccessful experience in the molten salt breeder experiment at Oak Ridge in handling molten fluorides under conditions of high temperature and moderately intense radiation (Weinberg 1957). A countervailing factor is the poorer tritium breeding capability of molten salts in comparison with pure lithium.

\section{Breeder Blanket}

Although the neutronics of breeding tritum in fusion reactors lies outside the scope of this article, it will be 
helpful to examine the constraints imposed by the need to maintain a neutron balance. In principle one neutron born in the plasrina can produce one triton by absorption in a lithium-6 atom-and something better than that by absorption in lithium-7. The capture cross section for the former is very high for thermal neutrons, i.e., low energy neutrons, and for the latter it is relatively high for fast neutrons. Numerous calculations have been performed for wide varieties of breeding systems to appraise the practicability of different choices of breeding media, moderators (to slow down the fast neutrons), structural materials, and cooling agents。

Two useful parameters for characterizing the breeding efficiency of a particular reactor system are the breeding ratio, namely, the number of tritons produced in the blanket per fusion neutron produced in the plasma, and the doubling time, which is the time required to produce a net amount of tritium over the fuel requirements of the plant equal to the total normal tritium inventory in the plant. For typical hypothetical designs these parameters range from 1.03 to 1.5 for the former and a few months for the latter.

For systems using natural lithium as both breeder and coolant it is possible to achieve satisfactory breeding ratios without additional neutron multipliers beyond the lithium-7. With another material as coolant, for example, helium, the volume of the blanket occupied by the cooling tubes and coolant results in lower breeding ratios, and the addition of beryllium is helpful in restoring the ratio. 
$: 2$

Systems involving molten salts typically require neutron multipliers for acceptable breeding ratios (Price 1973). In the case of fluorides the presence of beryllium fluoride is also necessary to lower the rnelting point of the salt to workable levels. The melting point of LiF is $848^{\circ} \mathrm{C}$, but a 50-50 mixture of $\mathrm{LiF}$ and $\mathrm{BeF}_{2}$ melts below $380^{\circ} \mathrm{C}$.

Although other salts have been considered as possible breeding media, only the fluorides have the ionic binding necessary for stability in a neutron radiation field together with practicable melting points and freedom from parasitic. neutron capture reactions. In principle lear, which has favorable: neutron multiplication characteristics, s.nuld he substituted for beryllium. The major argument for making this substitution, however, is that beryllium is a limited resource, but that argument is most probably invalid. Beryllium is a low $\mathrm{Z}$ element and is likely to be relatively abundant in the earth's crust. The fact that the known reserves are $1 \mathrm{ow}$ merely reflects the absence of a pressing need to find moré.

Studies of solid breeding media, conducted largely at the Brookhaven National Laboratory and in Japan have shown that adequate breeding can be obtained with a variety of materials including. LiAl and $\mathrm{LiPb}$ alloys, $\mathrm{Li}_{2} \mathrm{O}$ and lithium aluminates and silicates (Powell et al 1973). These systems necessarily require that the blanket be cooled by something like helium. 
Blanket Cooling

Except for the relatively small amounts of energy deposited in the first wall and the divertors all of the energy generated in tokamak type reactor systerns winds up in the blanket. The principal coolants proposed for removing this energy are lithium liquid, molten salts (lithium beryllium fluoride, in particular), and helium.

Liquid lithium circulating in a multiplicity of small loops and giving up its energy to boiling potassium has been proposed for the Oak Ridge design of Fraas (1973). The magnetohydrodynamic losses in transporting the lithium across the magnetic field lines have been shown to comprise less than one per cent of the power output of the machine based on experimental studies of a one-sixth scale test loop (Young et al 1975). Recent calculations for the use of lithium as coolant in UWMAK machines (Conn 1976) show that the pumping power requirements will approximate 1.5 per cent of the gross plant output. The maintenance of low pumping costs requires adroit engineering to ensure that the flow paths of the lithium minimize the crossing of the magnetic flux lines.

Lithium may be used as coolant at operating temperatures as high as $1000^{\circ} \mathrm{C}$ provided refractory metals like $\mathrm{Nb}-1 \mathrm{Zr}$ are used. If commercially available materials like stainless steel must be used, the maximum temperature is something like $500^{\circ} \mathrm{C}$. 
In principle it might be expected that molten salts could be useful coolants for fusion reactor blankets. They have relatively high heat capacities and are reasonably mobile in magnetic fields, and because of this mobility, their somewhat lower thermal conductivities (in comparison with metals) should still admit of a practicable heat transfer capability. Actually they are marginal heat transfer agents. Since their thermal conductivities are relatively poor, molten salts must be pumped at sufficient velocities to ensure adequate heat transfer by convective mechanisms. In the intense magnetic fields prevailing in the blanket of fusion reactors, 50 to $100 \mathrm{~K}$ gauss, high velocities may produce large electric potential differences between the salt and the walls wherever the salt flows normal to the magnetic field lines (Grimes and Cantor 1972). The effect of these potential differences: would be to promote electrolytic interaction between the.salt and metal with a sharp enhanrement of local corrosion of the metal walls. Thus it is likely that molten salts in fusion reactor blankets should only be moved in laminar flow through the blanket, in which flow regime they should not be used as coolants to any significant extent.

There is a further and much more stringent limitation on the usefulness of molten salts as coolants, and that is that they may permit the transfer of tritium from the reactor system to the steam cycle. This transfer could come about if (a) the coolant salt were circulated from the blanket directly through the steam generators of the power plant and (b) the molten 
salts permitted an appreciable tritium pressure at the walls of the stearn generator tubes.

Tritium can exist in molten fluorides as either molecular tritium or tritium fluoride depending on the oxidation state of the molten salt. As molecular tritium it will migrate to the bounding metal walls, and at the temperatures that prevail in the steam boilers it will dissociate at the tube wall surfaces and diffuse through the walls ultimately winding up in the steam; contaminating the steam and precluding any useful recovery of the tritium. As tritium fluoride it will also migrate to the tube walls and attack metals there according to reactions like

$$
2 \mathrm{TF}+\mathrm{M}+\mathrm{T}_{2}+\mathrm{MF}_{2}
$$

where $\mathbb{M}^{i}$ is a divalent metal, for example. Actually the tritiun formed in this reaction initially will be in nascent atomic form, and its tendency to permeate the metal wall might be greater than would be predicted from the equilibrium molecular tritium concentration.

The use of lithium as coolant suffers the same permeation disadvantage as molten salts except that the tritium pressures exerted by the same inventory of tritium in the breeder are much lower for lithium. Another difficulty with lithium is the possibility of greater hazard resulting from leaks in the steam generators that would mix lithium and water at high temperatures. 
The concern about tritium diffusion or leakage into the steam cycle arises from the fact that there is no economically practicable means for recovering the tritium. It exchanges readily with the hydrogen in the steam and would build up in the turbine hall inventory of boiler feed water and steam and ultimately be exhausted to the environment at rates equal to the diffusion and inleakage rates. Thus these rates must be kept below the total permissible tritium dump to the environment. Although no standards have yet been set for this release, it is anticipated that the maximum allowable release of radioactivity per plant site will be of the order of one curie per day. This tolerance translates to $10^{-4} \mathrm{~g}$ tritum per day, since tritium is the only source of atmospheric contamination from a fusion power plant under normal operating conditions (except, of course, thermal poliution).

The transport of tritium into the steam cycle can be prevented $b \bar{y}$ interposing a secondary heat transfer loop between the breeding medium and the steam cycle, with the secondary loop located outside the radiation field in the blanket... Since the secondary loop would not be exposed to neutron irradiation, it could use an efficient heat transfer medium like His (heat transfer salt) a molten eutectic mixture of sodium and potassium initrites and nitrates. The breeder fluid would give up energy'to the HTS in appropriate heat exchangers, and the HTS, in turn, would generate steam in the boilers.

The ITS is a particularly effective barrier for tritium transport because any tritium entering it would be bound up as 
water, for which the equilibrium pressure of molecular tritium is very low at the temperatures in the steam boilers.

There is a double penalty in capital costs resulting from the introduction of the secondary loop. First there is the cost of the loop itself. Second, since the intermediate heat exchangers can not be of infinite size, a finite temperature drop is required to drive them. As a consequence the steam cycle must operate at a lower temperature and correspondingly lower thermodynamic efficiency, and the overall size of the plant must increase for the same power output. Another tack that has been taken to minimize the tritium transport to the steam cycle has been to seek coatings for the steam generator tube walls to act as permeation barriers (Bell et al 1976, Maroni, Van Deventer et al 1976). If leaks are as important a mechanism for the tritium transport as permeation through metal walls, this tack might not be helpful. Under normal conditions of operation leaks between the blanket coolant and the steam would necessarily involve flow from the high pressure steam side into the coolant, which would be at much lower pressures. During emergency shutdowns and even planned turnrounds, however, leaks would inevitably lead to contamination of the steam if the coolant contained appreciable tritium pressures.

\section{Helium as Coolant}

As a consequence of all the possible difficulties involved in the use of hreeder fluids generally and molten 
fluorides in particular as blanket coolants, the PRD employs helium gas at about 50 atm pressure for cooling not only the blanket, but all other parts of the reactor system. Some tritium diffuses into the helium from the blanket and from surfaces in the divertor system, but its further diffusion into the steam c̈ycle or elsewhere is prevented by maintaining a modest oxygen pressure in the helium such that any hydrogenic species will oxidize to water on entering the helium. 'lhe effective tritium pressure is easily maintained below $10^{-16} \mathrm{~atm}$ by holding the watex pressure in the helium at $10^{-5}$ atm through the use of molecular sieve adsorbents or other gas-drying agents operating on a drag stream from the helium loop (Johnson 1975 ).

Helium has the advantage of being indifferent to the neutron flux in the blanket, and it is non-corrosive to conventional metals and alloys. The device of using modest oxygen pressures to control. tritium pressures however, does not work with refractory metals. Indeed even the trace anounts of oxygen in commercially pure helium result in severe corrosive attack on metals like niobium (DeVan 1972). For these systems the tritium control in the helium would have to be effected by maintaining a low hydrogen pressure in the helium under swamping conditions, i.e., high ratio of hydrogen (or deuterium) to tritiun. Unfortunately this tactic is constrained by the tendency for hydrogenic species to embrittle metals, and for refractory metals the tolerable hydrogen pressure is relatively low. 
Helium also has another serious disadvantage as coolant because of its low heat capacity. In order to carry off energy at high rate it must be pumped at very high pressures and very high velocities. For the PRD the pumping energy required for the coolant helium exceeds $4 \%$ of the gross output of the machine, $11.9 \%$ of the net electric power output.

\section{Tritium Recovery}

First generation fusion power plants based on the D-T fuel cycle must breed their own tritium to be economic. Estimated costs of tritium produced by current methods of manufacture range upwards from $\$ 3000$ per gram, which is too expensive for competitive power generation.

Since the fission of lithium by neutron bombardment is the only practicable means for producing tritium, the basic fuels for D-T fusion reactors are deuterium and lithium. Regardless of the particular form of the breeder, whether liquid metal, salt or solid, the breeding blanket must be of the order of a meter thick to ensure net breeding. Since the minor diameter of the reactor must be large enough for adequate plasma residence time, the total volume of the breeder blanket must be large and the associated mass of breeder therefore is also large. Thus the problem of tritium recovery is one of extracting small amounts of tritum from very large amounts of breeding medium under conditions that admit of quite complete collection and purification of the tritium. For example, in 
the PRD $0.585 \mathrm{~kg}$ of tritium is produced daily in $1.86 \times 10^{6} \mathrm{~kg}$ salt in the blanket.

The recovery must be effected at low concentrations to minimize ultimate permeation losses of tritium to the steam cycle and to avoid excessive solution of tritium in structures and subsequent embrittlement of the structures. Another constraint, of course, is the cost. Every kilogram of tritium tied up in inventury in first generation machines, i.e., before cheap tritium is available from fusion machines, represents a capital committment of, say, $\$ 3$ million.

At very large tritium inventories the natural radioactive decay of tritium to helium-3 will adversely affect. the doubling time for tritium breeding. Tritium has a half-life of 12.3 years, which corresponds to an instanteous loss rate of $5.62 \%$ per yoar. Thus, a plant w1th a total tritium inventory of $100 \mathrm{~kg}$ would lose $15 \mathrm{~g}$ per day throtlgh decay. Most cunceptual designs for fusion power plants fix the tritium inventory at lower values with the fuel reserve stockpile as the major element.

A more serious aspect of the radioactive decay of tritium is the deleterious effect of the helium formation within metal structures in exacerbating the embritting characteristics of the tritium.

For all of the foregoing reasons the tritium concentrations in the breeding media are held to very low values thereby complicating the recovery process. 


\title{
Tritium Recovery from Lithium Metal
}

\begin{abstract}
Tritium in liquid lithium readily forms lithium tritide, which, though relatively insoluble by normal standards, is much too soluble for fusion systems to permit tritium recovery by precipitation in a cold trap, even at temperatures just above the melting point of the lithium $\left(179^{\circ} \mathrm{C}\right)$.

Although some recent evidence suggests that trace amounts of the tritide may be found in the vapor phase, for all practical purposes the vapor - liquid equilibrium characteristics may be defined in terms of the dissociation reaction
\end{abstract}

$$
\mathrm{LiT}=\mathrm{Li}+\frac{1}{2} \mathrm{~T}_{2}
$$

The resulting expression for the solubility of tritium in lithium is of the form

$$
C=K_{s}(p)^{\frac{1}{2}}
$$

where $\mathrm{C}$ is the concentration of tritium in the liquid, $\mathrm{p}$ is the pressure of lrilium in the vapor and $K_{s}$ is a function of temperature called the Sievert's Law constant (Maroni 1974). Experimental studies at the Argonne National Laboratory 
(Maroni, Cataway, et al 1976) permit the evaluation of $\mathrm{K}_{\mathrm{S}}$ for al1 three hydrogen isotopes up to temperatures as high as $900^{\circ} \mathrm{C}$. Unfortunately the vapor pressures of tritium at low concentrations are so low relative to the vapor pressure of the lithium at any practicable temperature that distillation cannot affect a separation except in enormous equipment. Indeed it can be inférred that the lithium - tritium system will form an azeotrope at tritium concentrations of ahnut. $10^{-4}$ atom fraction, which is a higher concentration than is tolerable.

Fraas (1873) for hịs highl lemperalurc potāssium topping cycle fusion plant has proposed that tritium be recovered from the lithium by taking advantage of the high permeability of niobium to tritium at high temperatures. In a critical study of the problems of handling tritium in fusion reactors Watson (1972) concluded that permeation might be used for systems involving conventional metals 1ike stainless steel, but that it sould not bo uocd for refidelury tllelit systems bécause the duwnslredm tricium pressure could not be maintained low enough to drive the permeation process. With stainless steel, on the other hand, a small concentration of oxygen on the pressure side of the permeation window would tie ụp the tritium as water and maintain vanishingly 'small tritium pressures. Recent crpcrimcntal results uil the permeation of hydrogen through stainless steel reported by Axtmann et al (1976); however, suggest that even with zero pressure tritium on the downstream side the permeation rates at low driving pressures would be too low to be practicable. 
The problem here is that the permeation appears to be linearly dependent on the driving pressure rather than dependent on the square root of the pressure as occurs at higher driving pressures according to Richardson's expression

$$
J=\frac{P}{d}\left(P_{1}^{\frac{1}{2}}-P_{2}{ }^{\frac{1}{2}}\right)
$$

where $J$ is the permeation rate, $P$ is the permeability constant, $d$ is the thickness of the metal membrane, and the $p$ are the upstream and downstream tritium pressures. In the Axtmann study the linear law was found to hold for driving pressures as high as $10^{-2}$ torr. Since these results were obtained for hydrogen permeation from pure gas phase to gas phase of pure hydrogen, there are no mass transfer effects in the gas phases, and the observed rates may be presumed to be dependent solely on surface phenomena and transport within the metal. It might be argued that the fluxing action of fluids like liquid lithium and molten fluorides on typical metal surfaces would mitigate surface resistances to hydrogen permeation. However, Briggs (1971) in an analysis of the observed distribution of tritium throughout the equipment involved in the molten salt reactor experiment at the Oak Ridge National Laboratory found that the amounts were one thousand times lower than would be predicted from Richardson's equation.

It seems reasonable to conclude that permeation may be at best a marginal means for recovering tritium from liquid 
lithium 'untess fairly high tritium concentrations are permissible in the lithium. Unfortunately the refractory metals, which are best suited to permeation methods, are the least tolerant of tritium from the standpoint of metal embrittlement. Clearly we need a firm experimental base for appraising the possibilities here and also for gauging reliably the permeation losses throughout the reactor system. A detailed review of the permeation problem as it rèlates to fusion power development is given by Stickney (1972).

In principle tritium should be recoverable from lithium by chemical absorption using metal getters that have a higher affinity for tritium than does lithium and that are insoluble in lithium. A number of metals including yttrium and zirconium are possibilities. Hubberstey et al (1976) have undertaken preliminary experiments using yttrium eponge for cixtracting protium and deuterium from liquid lithium. The potential difficulties with this mode of tritum recovery are the contamination of the lithium with the getter metal and the structural stability of the getter on repeated thermal cycling resulting from periodic regeneration of the getter.

An alternative process for tritium recovery is liquid-liquid solvent extraction. Two different schemes have been proposed for this approach, one using molten salts as the solvent, the other using molten metal alloys.

Based on studies at the Argonne National Laboratory, Maroni, Wolison, and Staahl (1975) propose the use of eutectic mixtures of lithium chloride and potassium chloride as the 
solvent. The lithium tritide in the lithium is preferentially dissolved in the salt with a volumetric distribution coefficient of about 2. Their preliminary appraisal indicates that the process should be economically feasible provided their proposed but untested scheme for electrolytic recovery of the tritium from the solvent is practicable. Another potential difficulty aside from the ultimate recovery of the tritium from the salt is the possibility of contamination of the lithium by. the solvent salt.

Workers at the Los Alamos Scientific Laboratory propose the use of low melting point eutectic mixtures of metals containing yttrium, lanthanum or cerium (Anderson et al 1976). This process too is in a very prelimary state of investigaiton, but the distribution coefficient for tritium between these solvents and lithium exceeds 100 . Potential difficulties lie in the recovery of the tritium from the solvent and possible contamination of the lithium by elements of the solvent. The process is not strictly a solvent extraction since the basis for the separation is a chemical competition for the formation of tritides in the two phases.

Typical targets for maximum tritium concentrations in liquid lithium are $0.1 \mathrm{ppm}$ (atom parts per million) for systems operating at $1000^{\circ} \mathrm{C}$ and 1. ppm for systems operating at $500^{\circ} \mathrm{C}$, the former depending on permissible permeation rates through refractory metals and the latter dictated by tritium inventory considerations. It is not clear that any of the various schemes for tritium recovery now under consideration 
can achieve the desired tritium concentrations practicably. Given the many advantages of using liquid lithium as breeder, there are obviously strong incentives to find a suitable separation process. What is needed is chemical engineering ingenuity of the highest order.

Tritium Récovery from Molten Salts

Although the rccovery of trilium from molten filuorides apprears to be much simpler than for other breeders like lithium metal, the problem is not an easy one.

As pointed out previously, the tritium born of the fusion reactions in the blanket will exist as tritium fluoride for the most part with some present as molecular tritium and free tritium at the metal walls. For a power system like the PRD, formation of molecular tritium as a result of interaction between metal wall and tritium fluoride could be regarded as an advantageous feature of the tritium recovery system inasmuch as this tritium would permeate the walls and be recovered economical'y and completely from the coolant helium system. As a matter of tact, if all of the tritium production in the blanket were to Hollow this path and if the attack on the metal walls were uniform over the whole metal-salt interface, the walls would not require replacement before thirty years of operation. Since it would be unlikely that the corrosive attack could be maintained uniform, it would be desirable to minimize the corrosion by proper choice of metal walls and by doctoring up the salt with appropriate buffering agenț. 
DeVan (1976) has operated a flibe loop in 316 stainless steel at $700^{\circ} \mathrm{C}$ for more than 4500 hours with no detectable corrosion by the simple expedient of inserting a beryllium finger in the loop. Normally at these temperatures the chromium in the metal dissolves in the salt. On thermodynamic grounds it would be reasonable to expect that the beryllium would inhibit the formation of TF and hence any corrosive attack on the walls of a breeder salt system. The presence of the beryllium, of course, would be advantageous from the standpoint of the system neutronics by virtue of its neutron multiplication capability (Eq. 11).

Actually, if the molten salt is flowing through the blanket in laminar flow as is proposed for the Princeton machine, the maximum fraction of the tritium production which could permeate the metal walls under steady-state conditions, is less than one-third. Maienschein (1974) has shown that this maximum obtains regardless of the nature of the metal wall and the prociesses occurring at the salt-metal interface because the rate-limiting step is the diffusion of the tritium and tritium fluoride through the salt. Thus the bulk of the tritium recovery problem is the separation of the tritium fluoride from the molten salt under conditions which concentrate the tritium flunride. This separation is accomplished in the PRD by the system shown in Fig. 6. Table 5 lists the important characteristics. 


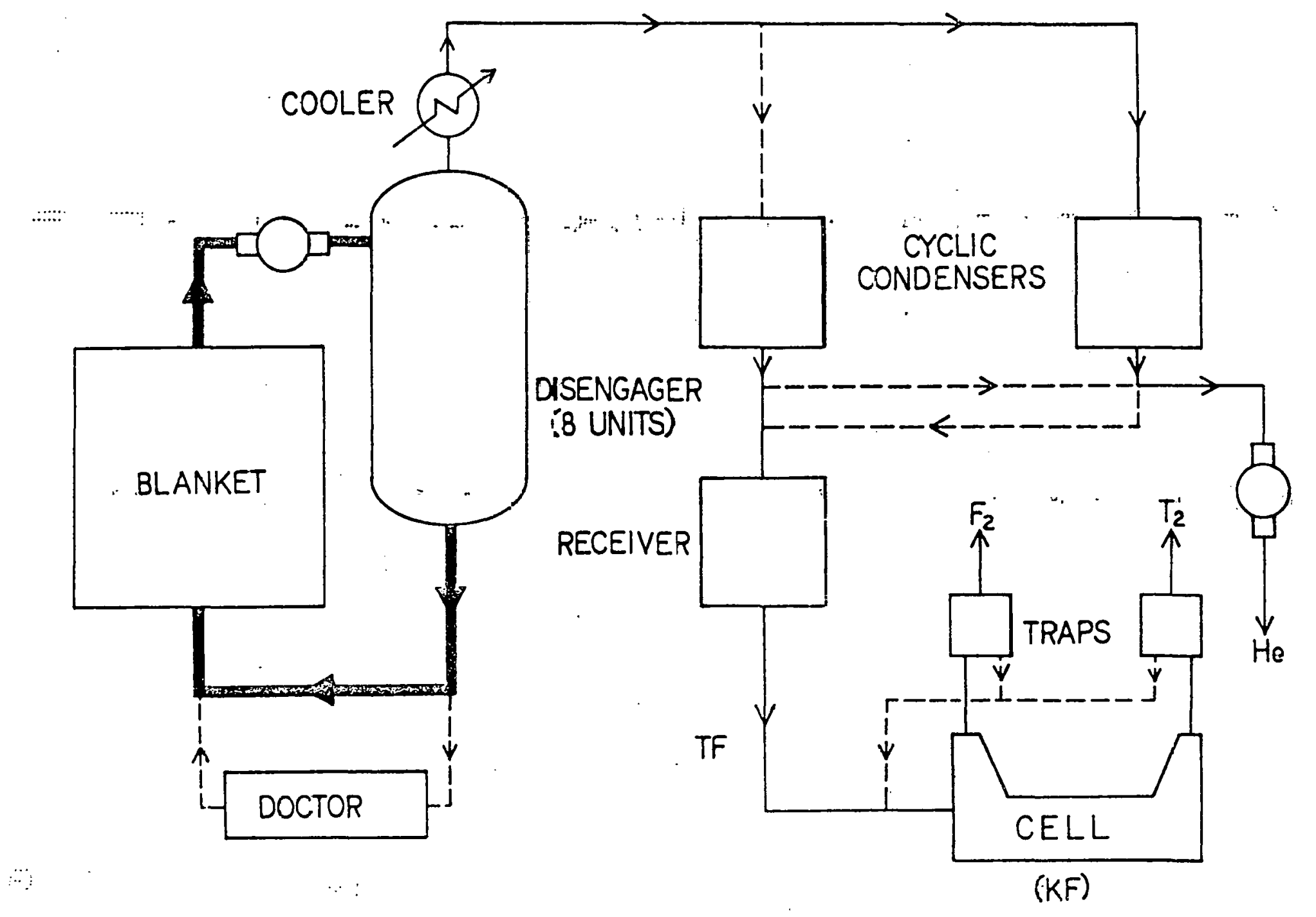

744450

Figure 6. Salt Processing System. 
Table 5. Some Characteristics of Tritium

Recovery System on Breeder Salt Loop

\author{
Salt Flow through Disengagers \\ $4.0 \times 10^{6} \mathrm{~kg} / \mathrm{hr}$ \\ Concentration of $\mathrm{TF}$ in Salt, mole fraction \\ Entering disengagers $2.1 \times 10^{-7}$ Exit disengagers $1.4 \times 10^{-7}$ \\ Composition of Gas Exit Diseng:ıgers, $\mathrm{N} / \mathrm{m}^{2}$. \\ $\mathrm{TF}$ \\ He \\ Sa.t.t \\ Tritium Recovery \\ Helium Ash Discharge \\ 10.1 \\ 15.6 \\ 13.2
}

Hot breeder salt from the reactor blanket recirculates continuously at a rate of $4 \times 10^{6} \mathrm{~kg}$ per hour through eight desorbers of disengagers distributed in parallel around the reactor system. In the $\mathrm{PRD}$ design the salt is sprayed in the form of small droplets into the desorbers which are maintained at pressures below $10 \mathrm{~N} / \mathrm{m}^{2}$. Tritium fluoride and helium gas together with small amounts of vaporized salt go off overhead, and the bulk of the salt collects at the bottom of the desorber and is pumped back through the blanket. A small drag stream on the salt is drawn off intermittently and run through a salt doctor to remove impurities and add buffering and other agents to maintain the desired salt composition. 
Maienschein (1974) and Talbot (1976) have shown that spray columns are likely to be marginal desorbers for recovering tritium from the salt. Getz (1976) has shown that packed column desorbers with the salt percolating down through conventional, packing', should, suftice, even for .individual, disengagers no larger than a meter in diameter and three meters high.

If the blanket is operated to produce molecular tritium rather than tritium fluoride, it would be necessary to introduce a small flow of fluorine into the desorber offgas to burn the tritium to the fluoride. This combustion should proceed rapidly at the temperatures exit the desorbers and not require elaborations of equipment or catalyst.

\section{Tritium Regeneration}

As can he seen from Fig. 6., the small flowe of gaoco leaving the top of each disengager are drawn first through a small cooler to knock out salt vapor and entrained salt, then through a: small trap cooled with boiling nilrogen to crystallizè out all the tritium fluoride.

The nitrogen cooled traps are thawed out periodically and the molten tritium fluoride is dropped to small electroytic cells wherëin melts of TF in KF are electrolyzed to $\mathrm{T}_{2}$ and $\mathrm{F}_{2}$ (Johnson 1972)。The respective gases are passed through cold traps to remove any $\mathrm{TF}$, the $\mathrm{T}_{2}$ then flowing to the primary fuel loop processing system and the $\mathrm{F}_{2}$ flowing to storage。 
Thermal Ballast

\begin{abstract}
Since tokamak reactor systems must operate cyclically, it is necessary to provide some kind of energy ballast to ensure that the delivery of electrical energy to the power grid is at constant rate. In the $\mathrm{PRD}$, the reactor is onstream about one hundred minutes and off three minutes. By maintaining an inventory of breeder salt three times the nominal holdup in the blanket, the salt can serve as a thermal ballast for the plant. During the offstream part of the cycle, when no energy is being produced, the salt flow bypasses the desorbers and merely circulates the blanket and storage system giving up its energy to the coolant helium. The average decline in salt temperature is only $50^{\circ} \mathrm{C}$ for an inventory of $6 \times 10^{6} \mathrm{~kg}$ salt.
\end{abstract}

\title{
Tritium Recovery from Solid Breeders
}

The principal problems with the use of solids as tritium breeders have to do with cooling and tritium recover. There seems to be no problem in achieving acceptable breeding ratios per se except that the requirement of high lithium density" conflicts with the need for flow channels for the coolant and short diffusion paths for the tritium.

Helium is the typical coolant, hence high gas pressures must be accommodated in the blanket. Since tritium diffusion rates in solids are much lower than in liquids, the solids must be sufficiently comminuted to ensure transport of the tritium into the helium. 
Wiswall and Wirsing (1976) have shown experimentally that tritium can be removed readily from solid LiAl, LiAlO 2 , and $\mathrm{Li}_{2} \mathrm{SiO}_{3}$ in the form of powder or small granules. For particles $:-$ not larger than 50 microns $(\mu \mathrm{m})$ maintained at temperatures not less than $300^{\circ} \mathrm{C}$, they estimate the tritium inventory "in a reactor blanket could be held to 10 curies/MW(e), i.e. $10^{-3} \mathrm{~g}$ tritium per megawatt of net electricity generating capacity. Tanaka et al (1976) have conducted $\dot{\hat{*}}$ similar experiments on pebbles of lithium oxide. This rinmpnind has the happy property that ito lithium denaity is higher than that of pure liquid lithium.

Gúggi et al (1976) present data on tritium release - rates from $\mathrm{LiAlO}_{2}$. Owen and Randall (1976): describe measurements at the Savannah River Laboratory for the same system and also for the distribution of helium and tritium throughout: irradiated Li-Al alloy. They present equilibrium data over, wide temperature ranges for all thrcc hydrogen isotopes in contact with lithium hydrides plus aluminum, LiAl alloy and: irradiated LiAl alloy. Veleckis and Maröni (1976) summarize results obtained at the Argonne National Taboratory on the thermodynamic properties of solutions of hydrogen i.sotopes in lithium and in lithium aluminum alloy. They show that the dissociation pressure of hydrogen in solution in the beta phase of 50-50 molar LiAl alloy is 25 fold greater than that for hydrogen in lithium at the same atom fraction hydrogen and same ternperature $\left(600^{\circ} \mathrm{C}\right)$. 
The original incentive for considering aluminum containing systems was to develop reactor systems with low enough residual radioactivity after normal operation to permit direct, as opposed to remote, maintenance. The principal penalty deriving from reliance on aluminum in reactor structures is that the operating temperatures are severely limited and overall thermodynamic efficiencies cannot be high. Although some clever designs have been proposed to circumvent the temperature limitations (Powell et al 1973), there remain formidable engineering problems to meet reliably the demanding constraints imposed on practicable power generators.

\section{Tritium Recovery from Helium}

Helium has been proposed as the blanket coolant for a wide variety of hypothetical designs. It is probably mandatory for blankets employing solid breeders or molten salt breeders, and even for blankets using other coolants helium is ususally proposed as the purge gas in piping jackets, valve shrouds and the like devices needed to prevent escape of tritium to the immediate environment. Thus essentially all reactor design systems will confront the problem of recovering tritium from helium, typically at very low tritium concentrations, and under conditions permitting nearly total recovery and easy regeneration as pure tritium.

For structural material.s like stainless steels which can tolerate oxygen in the helium the recovery system proposed 
for the PRD affords the simplest solution. Johnson (1975) has described the process in some detail. A small oxygen pressure corresponding to perhaps $50 \mathrm{ppm}$ is maintained in the coolant helium with the result that any tritium or other hydrogen isotope entcring the helium at the temperatures prevailing in blanket or divertors is oxidized to water. A drag stream comprising less than a per cent of the total helium flow $\left(5 \times 10^{3} \mathrm{~kg} / \mathrm{hr}\right.$ in the PRD) is taken off the coolant loop at the point of lowest helium temperature in the loop $\left(66^{\circ} \mathrm{C}\right)$ and circulated" through mole sieve adsorbers without turther cooling and at the operating pressures of the coolant, 50:atm. The relatively small adsorbers operating cyclically for regeneration have no difficulty in maintaining the water pressure in the helium below one $\mathrm{N} / \mathrm{m}^{2}$. In the regeneration step a given adsorber is heated to $260^{\circ} \mathrm{C}$ and pumped.. rnwn to $2 \times 10^{-6} \mathrm{~atm}$. The gases leaving the adsorber are drawn through small nitrogen cooled trans tin sondense out the water. Sume of the water will contain protium as a result of back-permeation from the steam side of the boilers into the helium. There will also be some deuterated water from permeation in the divertors. These isotopes are routinely separated in the fuel. processing: : system on the primary fuel lonp after the trappod out water is electrolized to hydrogen isotopes and oxygen.

While this process for recovering tritium from helium cannot be studied fully in the absence of intense neutron fluxes, it would be reasonable to infer that the effect of the neutrons largely ensure the establishment of 
thermodynamic equilibrium within the helium and hence ensure that all hydrogen would be oxidized to water. The rest of the problem is the drying of dry gases in a manner that permits complete recovery of the water.

For refractory metal reactor systems the helium would have to be maintained under reducing rather than oxidizing conditions and getters capable of removing hydrogen isotopes in the parts per billion range would be necessary. Schoenfelder and West (1976) have evaluated a number of getters including pure metals, alloys, supported metals and a high molecular weight ether.

Gettering the hydrogen isotopes is only half the problem; the other half is regenerating the isotopes. This step is apt to be slow (Watson 1972), but the isotopes come off as DT, TH etc., and as such can proceed to the primary fuel loop processing system for purification.

\section{Tritium Control}

The problem of tritium control, i.e., the restriction of releases to the environment, has already been alluded to, albeit briefly. In the PRD the problem is dealt with in a number of ways.

First, the turbine hall is isolated from the reactor building so that the only tritium entering the turbine hall is the closely controlled amount that leaks or permeates into the steam system from the coolant helium. Second, all lines or 
other elements carrying streams containing tritium are enclosed in jackets with a low pressure helium purge to interpose a tritium collecting barrier between the operating units in the reactor building and its atmosphere. A similar.purge is maintained"'between the blanket and the radiation shield protecting the magnets. Fourth, the atmosphere in the reactor building is monitored continuously for tritium, and in the event of a tritium repease into that atmosphere the energency system shown schematically in Fig. 7 is activated. The reactor building is essentially an hermetically sealed unit. Fifth and finally, the processing system system on the primary fuel loop, including the fuel stockpile, and hence most of the tritium inventory in the entire plant, is enclosed in a small bomb-proof, $\therefore$ quake-proof cell.

The technology of tritium control is pretty wall in hand, and no surprises are anticipated. Useful perspectives on th1s technology are given by.Hickman (1975) in a discussion of tritium problems in fusion reactor systems and by Garber (1976) in a detailed description of the tritium handling concepts used for the TFTR.

Fission-Fusion Hybrids

In the early days of the fusion program proponents of fusion power would cite cleanliness, inherent safety, and inexhaustable fuel supply as unique advantages of fusion power. These supposed advantages contrasted sharply with the 


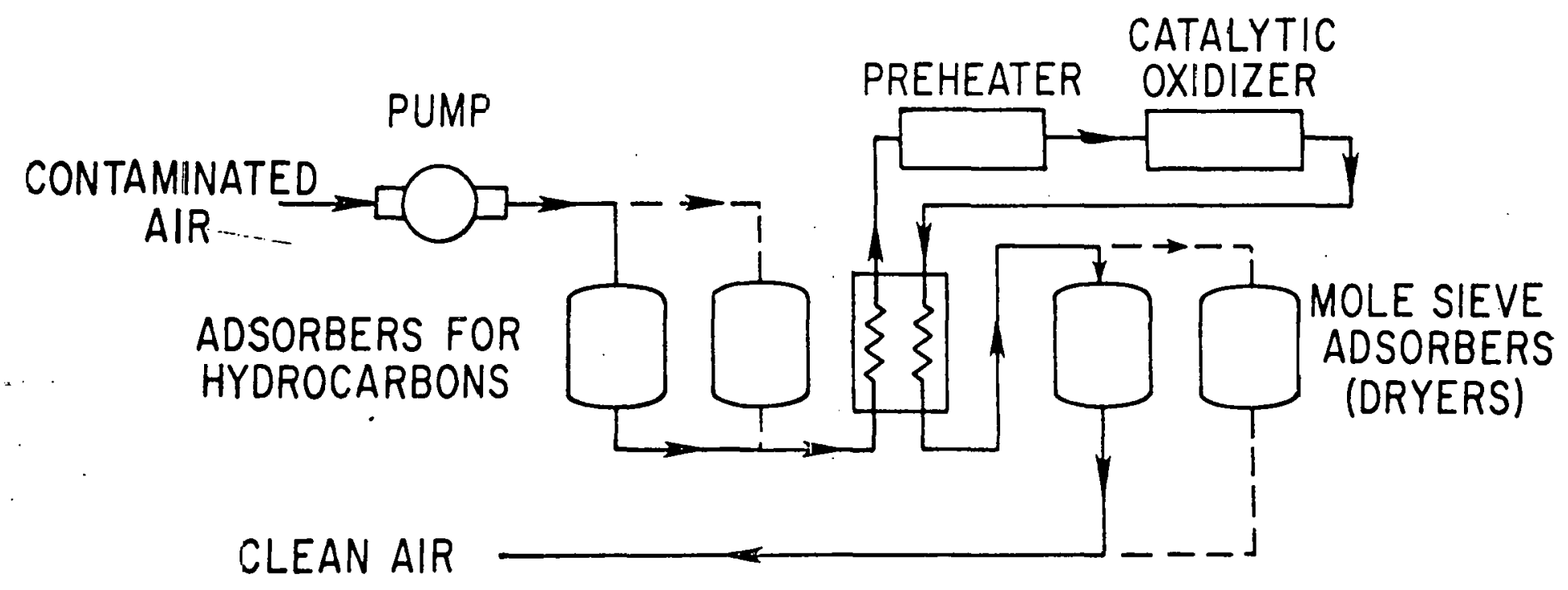

F-gure 7. Tritium Control System for Secondary Containment. 
$\because$

corresponding properties of fission power machines with their escalating production of long-lived radioactive wastes, their potential for disastrous runaway, and their reliance on scarce uranium reserves. As a consequence there was a marked reluctance on the part of many in the fusion community to contemplate even remotely the possibility of coupling fusion and fission machines in effective synergism. More recently our growing familiarity with the problems that beset fusion breeds a respect for them, and the idea of fission-fusion hybrids now commands a growing interest and activity.

Fustion reactions can produce a plethora of fast neutrons which can be used to drive fission reactions. Since the energy release per fission is tenfold that from a fusion event, the $:$ net result in principle is a substantial multiplication of energy production overall for a yiven size of fusion reactor. Furthermore, as Lidsky (1975) points out, hybrid machines can be used to breed fissile fuels, viz., plutonium from ordinary or depleted uranium or uranium-233 from thorium, and they can be used to transmute objertionable long-lived radioactive wastes to relatively harmless materials. As a consequence of these potential advantages a number of laboratories have undertaken studies of hypöthetical fission-fusion hybrid machines. For example, the Princeton Plasma Physics Laboratory is designing a machine based on the TFTR but inciuding a blanket in which tritium is bred in a manner similar to the $\mathrm{PRD}$ and plutonium is produced form uranium and subsequently burned. 
The original concept was a machine not much larger than the TFTR, and like the TFTR, driven by energetic neutral beams of deuterons, i.e., the injected energy would be necessary to sustain the fusion reactions. A blanket surrounding the reactor would simultaneously breed tritium from lithium and plutonium from uranium and derive further energy from fission of the plutonium. Although the study has not been completed, the results so far (Tenney 1976) suggest that the machine will have to be much larger than the TFTR, more nearly approaching the dimensions of the PRD, and it will probably be best suited to power generation rather than plutonium production.

The chemical engineering problems posed by the hybrid differing from those of the fusion machine alone include the reprocessing of partially converted uranium, presumably from solid slugs, the recovery of tritium from systems now complicated by the presence of uranium and plutonium, and the removal of radioactive fission wastes. These problems, though by no means trivial, are of secondary importance in exploring optimal combinations of fusion and fission capabilities. The problems of the plasma physics still dominate the constraints on possible designs.

\section{Conclusion}

This brief survey necessarily glosses over many problems in fusion development. It should be clear, however, that many of the technological problems are uniquely suited to 
chemical engineering. Because of the extreme conditions and inordinate constraints the problems are difficult and challenging. Indeed in a recent appraisal of current fusion research Metz (1976) concludes that the problems appear overwhelming. Although his appraisal was focussed on the plasma physics and materials problems, it would be easy to come to the same conclusion about some of the other probleme discussed in this review.

On the other hand, it is true that fusion power is olcan by cumparlson with tission power, it is inherently safer, and its ultimate fuel 1 s available in limitless supply at essentially zero cost. Although its capital costs are necessarily high, it is hard to see that those for fission breeders or solar power for large scale power generation could ever be markedly less overall.

Given the difficulties of the problems remaining to be solved, fusion power must be regarded as a long range solution to our energy needs. But it is a solution, and probably the best one. $\because$ To realize practicable fusion power will require a major and continuing scientifir and engineering committment. The fact that we are well launched in that committment is a happy exception to the notion that long range planning is impunutble in democracies.; 


\section{ACKNOWLEDGMENT}

This work was supported in part by U.S. Energy Research and Development Administration Contract E(11-1)-3073. 


\section{LI'LERATURE CITED}

Anderson, J。L。, Carstens, D. H. W., and Alire, R. M., CTR Related Tritium Research at LASL, proceedings 으 the International Conference on Radiation Effects and Tritium Technology for Fusion Reactors, J. S. Watson, and J. W. Wiffen, eds. (National Technical Information Service, Springfield, Virginia, 1976) CONr-750989, Vol. III, pp. 396-415.

Axtmann, R. C., Johnssọn, E. F., and Kuehler, C.W., Permeation of Hydrogen at Low Pressures though Stainless Steel. and Implications for Tritium Control in Fusion Reactor Systems, ibid., Vol. IV, pp. 361-378.

Beli, J. T., Redman, J. D., Strehlow, R. A., and Smith, F. J., Tritium Permeation through Steam Generator Materials, Ibid:, Vol. İV̄, pp. 317-328.

Briggs, R。 B., Tritium in Molten Salt Reactors, Reactor Technology $14,335(1971-2)$.

Burnett, S. C。, Elhs, W. R。, Oliplant, and Ribe, F。 L., A Reterence Theta Pinch Reactor (RTPR), Los Alamos Scientific Laboratory Report LA-5121-MS (1972). 
Conn, R. W., Selected Conclusions from the UWMAK-I, II, and III Reports Relating to Blanket and Shield Problems, presented orally at the Technology Workshop on Blanket/Power Systems for Fusion Reactors, 29 March 2 April 1976, Brookhaven National Laboratory, to be published.

Davis, J. W., and G. L。 Kulcinski, Major Features of D-T Tokamak Fusion Reactor Systems, Electric Power Research Institute Interim Report EPRI 472-1 (1976)。

Dawson, J. M., Furth, H。 P॰, and Tenney, F. H., Production of Thermonuclear Power by Non-Maxwellian Ions in a Closed Magnetic Field Configuration, Phys. Rev. Letters $\underline{26}$, 1156 (1971)。

DeVan, J. H., Compatibility, Fusion First Wall Materials, U.S. Atomic Energy Commission Report WASH-1206 (1972).'

DeVan, J. H., private communication (1976)。

Fraas, A. Po, Conceptual Design of the Blanket and Shield Region and Related Systems for a Full-Scale Toroidal Fusion Reactor, Oak Ridge National Laboratory Report ORNL-TM-3096 (1973). 
Frias, A. P., Comparative Study of the More Promising Combinations of Blanket Materials, Power Conversion Systems, and Tritium Recovery and Containment systems for Fusion Reactors, Oak Ridge National Laboratory Report ORNL-TM-4999 (1975). $\because$

$$
\begin{aligned}
& \therefore \\
& \because
\end{aligned}
$$

जarper, H. J., TFTR Tritium Handling Concepts, Proceedings of the International Conference on Radiation Effects and Tritium Technology for Fusion Reactors, op. cit., V̌l. III, pp. 347-395.

Getz, G. A., Packed-Column Removal of Tritium Fluoride from Fusión Reactor Molten Salt Breeder, senior thesis, Princeton University, Princeton, New Jersey (1976).

Gralnick, S. L., Fuel Injection in $\underline{\text { Fusion }} \underline{\text { Power }}$ Plant, R。 G. Mills, ed., Princeton Plasma Physics Laboratory Report MATT-1050 (1974), Chapter 7 .

Grimes, W. R., and Cantor, S., Molten Salts as Blanket Fluids in Controlled Fusion Reactors in The Chemistry of Fusion Technology, 'D. M. Gruen, ed. (Plenum Press, New York, 1972) pp. 161-190.

Guggi, D。, Ihle, H., Neubert, A。, and Wolfle, R。, Tritium Release from LiAlo, Its Thermal Decomposition and Phase Relationship - LiAlO - LiAl O, Implications Regarding $\because$ : 
Its Use as Blanket Material in FRT, Proceedings International Conference Radiation Effects and Tritium Technology for Fusion Reactors, Gatlinburg, Tenn., Vol. III, pp. 416-432 (1976).

Hafele, W., A Systems Ápproach to Energy, Am Scientist 62, pp. 438-447 (1974).

Hickman, R. G., Tritium Problems in Fusion Reactor Systems, Proceedings Symposium on Tritium Technology Related to Fusion Reactor Systems, W. H. Smith, W. R. Wilkes, and L. J. Wittenberg, eds., USERDA Report ERDA-50, pp. 76-36 (1975)。

Homeyer, W. G., Thermal and Chemical Aspects of the Thermonuclear Blanket Problem, MTT Research Laboratory of Electronics Technical Report No. 435 (1965).

Hottel, H. C., Solar Energy, Chem. Eng. Progr. 71, No. 7, pp. '53-65 (1975).

Hubbard, H. W., Martinel1i, E. A., and Hammond, R. P., The Pacer Plan, Science 188, 780 (1974).

Hubberstey, P., Adams, P. F., and Pulham, R, J., Hydrngen Isotope Removal from Liquid Lithium; Use of Yttrium Sponge as Getter, Proceedings International Conference Radiation Effects and Tritium Technology for Fusion Reactors, Gatlinburg, Tenn., Vol. III, pp. 270-288 (1976). 
Johnson, E. F., Appraisal of Possible Stéllarator Blanket Systems, USAEC Report NYO-7900, Princeton University, Princeton, New Jersey (1957).

Johnson, F. F., Fusion Reactor Fuel Processing, in The Chemistry of Fusion Technology, D. M. Gruen, ed., Plenum Press, New York, :pp. 191-214 (1972).

Johnson, E. F., Fuel Handling, Chapter 14, in A Fusion Pnwer Plant, R. G. Milla, cd, Plazma Physics Láluralury Repurt MATT-1050, Princeton University, Princeton, New Jersey (1974).

Johnson, E。 F., The Use of Molecular Sieves for Tritium Control in*:Fusion Power Plants, AIChE Symposium Ser. No. 152, 71, pp. 114-120 (1975).

Kintner, E。 E., An Overview of the U. S. Fusion Program, Proceedings International Conference Radiation Effects and Tritium Technology for Fusion Reactors, Gatlinburg, Tenn., Vol. I, pp. 1-16 (1976)。

Kulcinski, G。 L。, Radiation Damage: The Second Most Serious obstacle to Commereialization of Fusion Power, ibid., Vol. I, pp. 17-72 (1976).

Lawson, J. D。, Some Criteria for a Power "Producing Thermonuclear Reactor, Proc. Phys. Soc。 (London) B70, 6 (1957). 
Lidsky, L. M., Fission-Fusion Systems: Hybrid, Symbiotic and Augean, Nucl. Fusion 15, pp. 151-173 (1975).

Maienschein, J. L., A Study of Tritium Removal from Molten Salts in a Fusion Power Reactor, Senior Thesis, Princeton University, Princeton, New Jersey (1974).

Maroni, V. A., Tritium Distribution and Leakage, Chapter 15 in A Fusion Power Plant, R. G. Mills, ed., Plasma Physics Laboratory Report MATT-1050, Princeton University, Princeton, New Jersey (1974).

Maroni, V. A., Wolson, R. D., and Staahl, G. E., Some Preliminary Considerations of a Molten Salt Extraction Process to Remove Tritium from Liquid Fusion Reactor Blankets, Nucl. Tech., 25, 83 (1975).

Maroni, V. A., Calaway, W. F., Veleckis, E., and Yonco, R. M.,. Solution Behavior of Hydrogen Isotopes and Other Non-Metallic Elements in Liquid Lithium, Proc. International Conference Liquid Metal Technology in Energy Production, May, 1976, Champion, Pa?, to be published.

Maroni, V. A., Van Deventer, F. H., Renner, T. A., Pelto, R. H., and Wierdak, C. J., Experimental Studies of Tritium Barrier Concepts for Fusion Reactors, Proceedings International Conference Radiation Effects and Tritium Technology for Fusion Reactors, Gatlinburg, Tenn., Vol. IV, pp. $329-360(1976)$. 
Metz, W. D., Detailed Reactor Studies Identify New Problems; Science 193, pp. 38-40, 76 (1976).

Mills, R. G., Lawson Criterion, Plasma Physics Laboratory Report MATT-844, Princeton University, Princeton, New Jersèy, May 1971.

Mil1s, R. G., An Introduction to Fusion Power Reactors, Chapter 7 in A Short Course in Fusion Power, Princeton University, Prinçeton, New Tersey (1972).

Mills, R. G., A Fusion Power Plant, Plasma Physics Laboratory Report MATT-1050, Princeton Univeristy, Princeton, New Jersey (1974). (Avä̈lable from National Technical Information Service, Springfield, Virginia)

Owen, J. H., and Randall, D., Equilibrium and Kinetic Studics of Systems of Hydrogen Isotopes, Lithium. Hydrides, Aluminum, and LiAlo, Proceedings International Conference Radiation Effects and Tritium Technology for Fusion Reactors, Gatlinburg, Tenn., J. S. Watson and F. W. Wiffen, eds., Vol. III, pp. "443-457 (1976).

Peterson, M. A., Werner, R. W., Hoffman, M. A., and Carlson, G. A., A Modularized Mirror Fusion Reactor Concept with Emphasis on Fabricability, Assembly, and Disassembly, UCRL-75826, Lawrence Livermore Laboratory, Livermore, Cal., October 1974 . 
Post, R. F., and Ribe, F. L。, Fusion Reactors as Future Energy Sources, Science 186, pp. 397-407 (1974).

Powell, J. R., Miles, F. T., Aronson, A., Winsche, W. E., Studies of Fusion Reactor Blankets with a Minimum Radioactive Inventory and with Tritium Breeding in Solid Lithium Compounds: A Preliminary Report, BNL-18236, Brookhaven National Laboratory, Upton, New York, June 1973.

Price, W. G., Jr., Blanket Neutronic Studies for a Fusion Power Reactor, Trans. Am. Nuc1. Soc. 17, 35-7 (1973).

Rose, D. J., Nuclear Electric Power, Science 184, 351-9 (1976).

Schoenfelder, C. W., and West, L. A., Tritium Removal: An Evaluation of Several Getters, Proc. International Conf. Radiation Effects and Tritium Technology for Fusion Reactors, Gatlinburg, Tenn., T. S. Watson and F. W. Wiffen, eds., Vol. III, pp. 482-506 (1976).

Spitzer, L., Grove, D。 J., Johnson, W. E., Tonks, L., and Westendorp, W. F., Problems of the Stellarator as a Useful Power Source, USAEC Report NYO-6047, Princeton University, Princeton, New Jersey (1954). 
Stickney, R. E., Dịftusion and Permeation of Hydrogen Isotopes in Fusion Reactors, in The Chemistry of Fusion Technology, D. M. Gruen, ed., Plenum Press, New York, pp. $241-320$ (1972).

Talbot, J。 B., A Study of Tritium Removal from Fusion Reactor Blankets of Molten Salt and Lithium Aluminum, USERDA Report ORNL/TM-5104, Oak Ridge National Laboratory, Oak Ridge, Tenn. , May 1976 .

Tanaka, K., Kudo, H., and Amano, H., Tritium Recovery from Lithium Oxide Blanket, Proceedings International Conference Radiation Effects and Tritium Technology for Fusion Reactors, Gatlinburg, Tenn., J. S. Watson and F. W. Wiffen, eds., Vol. III, pp, 253-269 (1976).

Tenney, F. H., privale cumnunicátion (1976).

Watson, J. S., An Evaluation of Methods for Recovering 'l'ritium from the Blankets or Conlant systeme of Fusion Reactors, IUSAEC Report ORINL-TM-3794, Oak Ridge National Laboratory, Oak Ridge, Tenn., July 1972.

Watson, J。S., and Wiffen, F. W., eds., Proceedings International Conference Radiation Effects and Tritium Technology for Fusion Reactors, Gatlinburg, Tenn., USERDA Conf-750989, Oak Ridge National Laboratory, Oak Ridge, Tenn., March 1976. Available from NTIS。 
Weinberg, A。 M。, Molten Fluorides as Power Reactor Fuels, Nucl. Sci。Eng。2, pp. 797-803 (1957).

Wilkes, W。 R., Separation of Hydrogen Isotopes for Tritiurn Waste Removal, Proc. Symp. on Tritium Technology Related to Fusion Reactor Systems, W. H. Smith, W. R. Wilkes, and L. J. Wittenberg, eds., USERDA Report ERDA-50, 113-9, June 1.975 .

Wiswall, R. H., and Wirsing, E., Tritium Recovery from Fusion Blankets Using Solid Lithium Compounds - II: Experiments on Tritium Removal and Absorption, Proc. International Conference Radiation Effects and Tritium Technology for Fusion Reactors, Gatlinburg, Tenn., J. S. Watson and F。W. Wiffen, eds., Vol. III, pp. 232-252 (1976).

Young, F. J., Holcomb, R. S., and Fraas, A。 P., Magnetohydrodynamic Test of a One-Sixth Scale Model of a CTR Recirculating Lithium Blanket, USERDA Report ORNL-TM-4818 (1975). 